WSRC-TR-2003-00444

Revision 0

Determination of Co-60 in Cobalt Slugs and Slabs and Radionuclides in Curium Sampler Slugs in L-Reactor Disassembly Basin

Vito R. Casella, Saleem R. Salaymeh, Frank S. Moore and Raymond A. Sigg

December 10, 2003

Westinghouse Savannah River Company Savannah River Site

Aiken, SC 29808

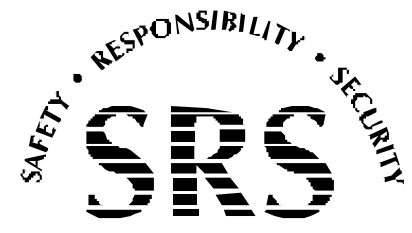


This document was prepared in conjunction with work accomplished under Contract No. DE-AC09-96SR18500 with the U. S. Department of Energy.

\section{DISCLAIMER}

This report was prepared as an account of work sponsored by an agency of the United States Government. Neither the United States Government nor any agency thereof, nor any of their employees, makes any warranty, express or implied, or assumes any legal liability or responsibility for the accuracy, completeness, or usefulness of any information, apparatus, product or process disclosed, or represents that its use would not infringe privately owned rights. Reference herein to any specific commercial product, process or service by trade name, trademark, manufacturer, or otherwise does not necessarily constitute or imply its endorsement, recommendation, or favoring by the United States Government or any agency thereof. The views and opinions of authors expressed herein do not necessarily state or reflect those of the United States Government or any agency thereof.

This report has been reproduced directly from the best available copy.

Available for sale to the public, in paper, from: U.S. Department of Commerce, National Technical Information Service, 5285 Port Royal Road, Springfield, VA 22161, phone: (800) 553-6847, fax: (703) 605-6900

email: orders@ntis.fedworld.gov

online ordering: http://www.ntis.gov/help/index.asp

Available electronically at http://www.osti.gov/bridge

Available for a processing fee to U.S. Department of Energy and its contractors, in paper, from: U.S. Department of Energy, Office of Scientific and Technical Information, P.O. Box 62, Oak Ridge, TN 37831-0062,

phone: (865)576-8401,

fax: (865)576-5728

email: $\underline{\text { reports@ adonis.osti.gov }}$ 
This page intentionally left blank 
WSRC-TR-2003-00444

Revision 0

December 10, 2003

Page 4 of 41

\begin{abstract}
Using a sodium iodide detector and multichannel analyzer system and an underwater collimator assembly, Co-60 concentrations were determined for 548 L-Reactor Disassembly Basin cobalt slugs and slabs and 18 curium sampler slugs. The total activity of all of the assayed slugs summed to 31,783 curies. From the Co-60 concentrations of the curium sampler slugs, the irradiation flux was determined for the known irradiation time. The amounts of Pu-238,239,240,241,242; Am241,243; and Cm-242,244 produced were then obtained based on the original amount of Pu-239 irradiated.
\end{abstract}


WSRC-TR-2003-00444

Revision 0

December 10, 2003

Page 5 of 41

This page intentionally left blank. 


\section{TABLE OF CONTENTS}

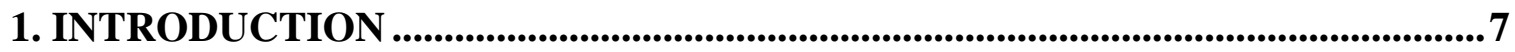

2. EXPERIMENTAL ...................................................................................................................8

Instrument Setup for Cobalt Slugs and Slabs....................................8

Instrument Setup for Curium Sampler Slugs.................................12

Calibration........................................................................12

System Quality Assurance and Quality Control................................13

3. ANALYSIS AND RESULTS ............................................................................................14

Cobalt Slug and Slab Analysis and Results....................................14

Curium Sampler Slug Analysis and Results.................................29

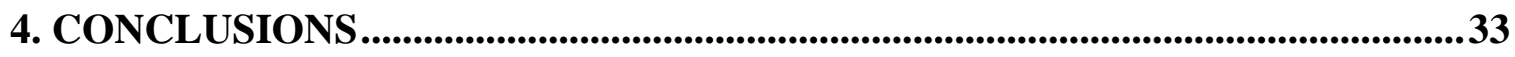

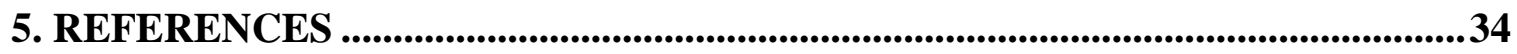

\section{LIST OF FIGURES}

Figure 1. Sketch of L-Area cobalt assay instrument assembly with Na I detector.... 9 Figure 2. NaI detector arrangement for counting standard C0-60 source............10 Figure 3. Underwater cobalt assay assembly showing measurement platform, RO7 monitor and slug bins...........................................................................................................10 Figure 4. Typical background and Co-60 standard NaI spectra.......................11 Figure 5. Control chart for Co-60 standard check source $(6 / 11 / 03$ - 8/20/03)........14 Figure 6. Typical slug spectrum with regions of interest for Cs-137 and Co-60.....15 Figure 7. NaI count $(\mathbf{5 0 , 0 0 0} \mathrm{sec})$ at collimator tray distance of $2 \%$ " with collimators removed...................................................................................29

Figure 8. HPGe 50,000 sec count of curium sampler slug $0654 \ldots \ldots \ldots \ldots \ldots \ldots \ldots \ldots . . . . .33$

\section{LIST OF TABLES}

Table 1. Curies of Co-60 in L-Area basin cobalt slugs and slabs....................................16

Table 2. Activities produced from irradiation of 18 curium sampler slugs............32

\section{APPENDIX}

Appendix 1. Qualification Plan for Characterizing Cobalt Slugs in L-Basin.............35 Appendix 2. Microshield calculation for curium sampler slug geometry correction.38 
WSRC-TR-2003-00444

Revision 0

December 10, 2003

Page 7 of 41

\title{
Determination of Co-60 in Cobalt Slugs and Slabs and Radionuclides in Curium Sampler Slugs in L-Reactor Disassembly Basin
}

\author{
Vito R. Casella, Saleem R. Salaymeh, Frank S. Moore and Raymond A. Sigg \\ Westinghouse Savannah River Company \\ Savannah River Site \\ Aiken SC 29808
}

\section{INTRODUCTION}

Co-60 was historically produced in the SRS reactors for private vendors and the United States military. Cobalt slugs were irradiated in the early 1970s. Post-production, remaining cobalt slugs (including slab form) were consolidated for storage in L-Basin. There are approximately nine hundred cobalt slugs currently stored in L-Basin awaiting final disposition. These slugs had historically incomplete documentation for activity rates; therefore, assaying was required in order to determine their activity levels.

Since the gamma dose rate from these slugs is extremely high, the most cost effective way to shield a source of this magnitude from personnel and the radiation detector was to use the basin water in which the slugs are stored as the shield. A sodium iodide gamma detector was placed above a specially designed air collimator assembly, so that slug was at least eight feet from the detector and was shielded by the basin water.

The assaying took part in two phases. The first phase was in 1999. Assays were taken as slugs were being consolidated from K-Basin to L-Basin and also for a portion of the slugs already stored in L-Basin. ${ }^{1-3}$ As these slugs were assayed, they were placed in tag-holders, then into labeled buckets for storage. The second phase of assaying has just been completed for the remainder of slugs that were stored in L-Basin prior to 1999, as part of the current disposal effort. The slugs that were recently assayed in the second phase were placed in numbered bins with procedurally specified activity ranges.

Seventy-two cobalt slugs were originally stored at Savannah River Technology Center (SRTC) irradiation facility with a decay-corrected activity of 36,000 curies. These slugs were recently transferred to L-Basin in an 8-Ton Cask as part of the disposition effort, and were the only slugs with documentation of original activity rates. ${ }^{4}$

All of the slugs previously stored in the basin and the SRTC slugs are to be disposed of as "lowlevel waste" at the Solid Waste facilities. In order to permanently minimize radiation exposure from this intense Co-60 source, an obsolete Paducah Demonstration Cask (also slated for waste disposal) will be utilized to provide shielding via depleted uranium layers within the cask. 
WSRC-TR-2003-00444

Revision 0

December 10, 2003

Page 8 of 41

In addition to the cobalt slugs, there are 18 curium sampler slugs ${ }^{5}$ (also called Pu monitor pins) that were used to produce $\mathrm{Cm}-244$ from $\mathrm{Pu}-239$; these slugs will be disposed of with the Co-60. Very little information exists on the isotopic content of these slugs. Therefore, in addition to the Co-60 assay, the sampler slugs were also analyzed with a High Purity Germanium (HPGE) detector in an attempt to identify any additional radioactive nuclides in them.

\section{EXPERIMENTAL}

\section{$\underline{\text { Instrument Setup for Cobalt Slugs and Slabs }}$}

An air filled collimator had been designed to allow a small pencil of gamma radiation from the slug to reach the detector, a 2"x 2" NaI crystal. ${ }^{2}$ Eleven feet of basin water provided the gamma ray shielding. Figure 1 is a sketch of the collimator used in data acquisition. The collimator consists of a tray to hold the slug that was placed below the lower end of the collimator, a 48"x $3 / 4$ " pipe, a 1 1/4" x 48"aperture holder containing five 15/16" x 1/8" aperture pieces and a packet of BBs that disperse the Co-60 gamma rays.

Two measurement systems were used for determining the quantity of Co-60 in the cobalt slugs and slabs and the curium sampler slugs. ${ }^{6}$ For most of the slug and slab measurements, analyses were performed with a portable multichannel analyzer (MCA) EG\&G Dart system, containing a laptop computer with GammaVision software. Since the EG\&G Dart system became inoperable in the very hot and humid environment, it was replaced with another system that consisted of a portable computer with a Canberra NaI+ card installed and Genie 2000 software. This card converts the PC to a full function MCA and contains the ancillary electronics, high voltage power supply and amplifier, required for data acquisition. A 2" x 2" NaI detector was used and data were stored on floppy disks for subsequent review and analysis and retention. The spectra were acquired in the energy range $0-2 \mathrm{MeV}$ with an ADC gain of 512 channels and with the detector high voltage set to $+800 \mathrm{~V}$. Pictures of the NaI detector arrangement and underwater cobalt assay assembly are shown in Figures 2 and 3.

For analysis of the curium sampler slugs, the analysis system consisted of a portable high purity germanium detector, a personal computer with a Canberra Accuspec card and Genie 2000 software, a high voltage power supply, an analog-to-digital converter, and an amplifier.

The gamma ray spectrum from Co- 60 consists of two gamma rays, one at $1.17 \mathrm{MeV}$ and the other at $1.33 \mathrm{MeV}$. A "region of interest" (ROI) was defined around these two gamma rays in the spectrum, and the number of counts in this region summed by the MCA software. This provided the data necessary to assay the slugs. A background spectrum and a cobalt standard spectrum are shown in Figure 4. The two prominent Co-60 peaks can be seen with the ROI markers around them, and a Cs-137 peak from the basin water is also seen. 
WSRC-TR-2003-00444

Revision 0

December 10, 2003

Page 9 of 41

\section{Cobalt Assay Instrument}

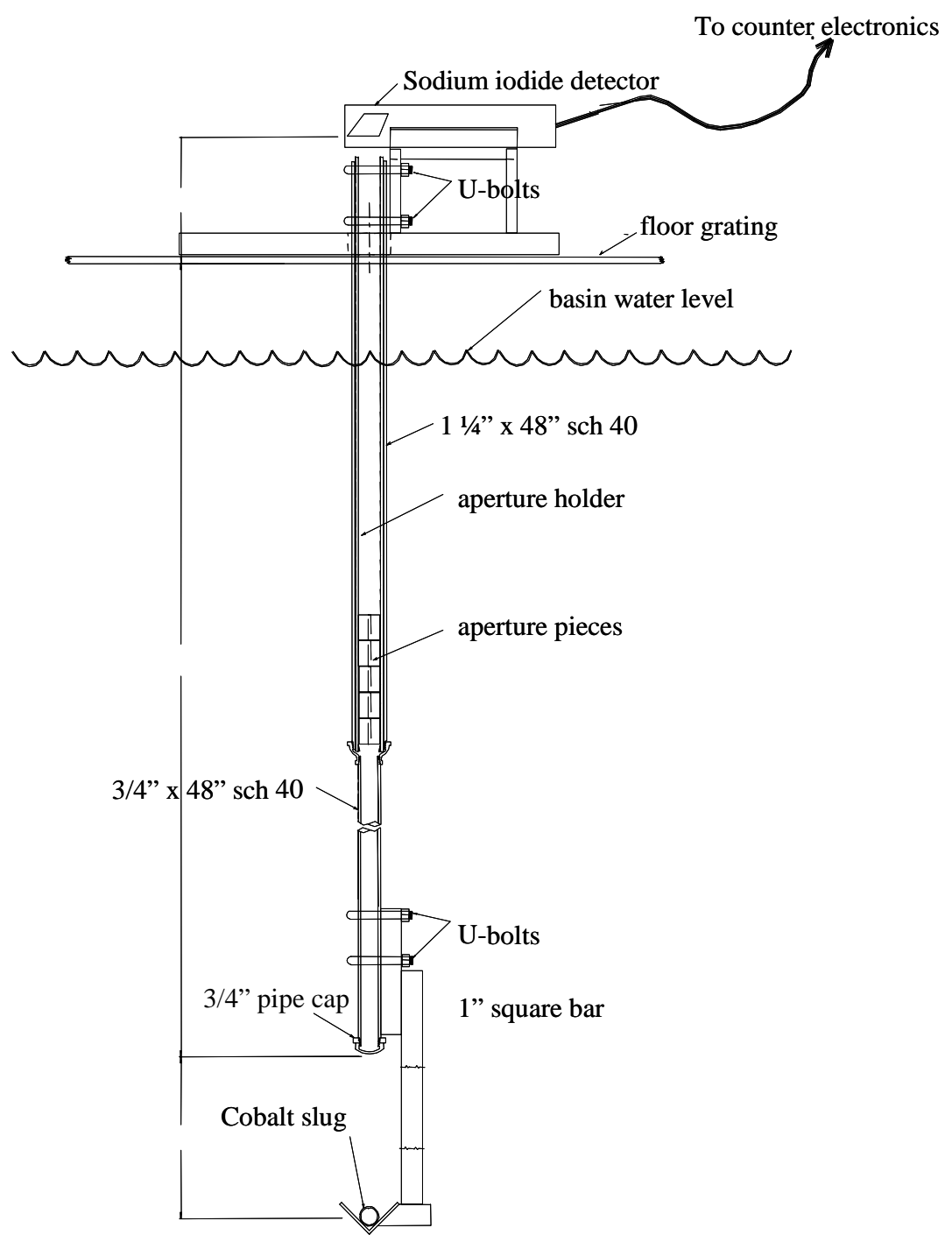

Figure 1. Sketch of the L-Area cobalt assay instrument assembly with NaI detector. 
WSRC-TR-2003-00444

Revision 0

December 10, 2003

Page 10 of 41

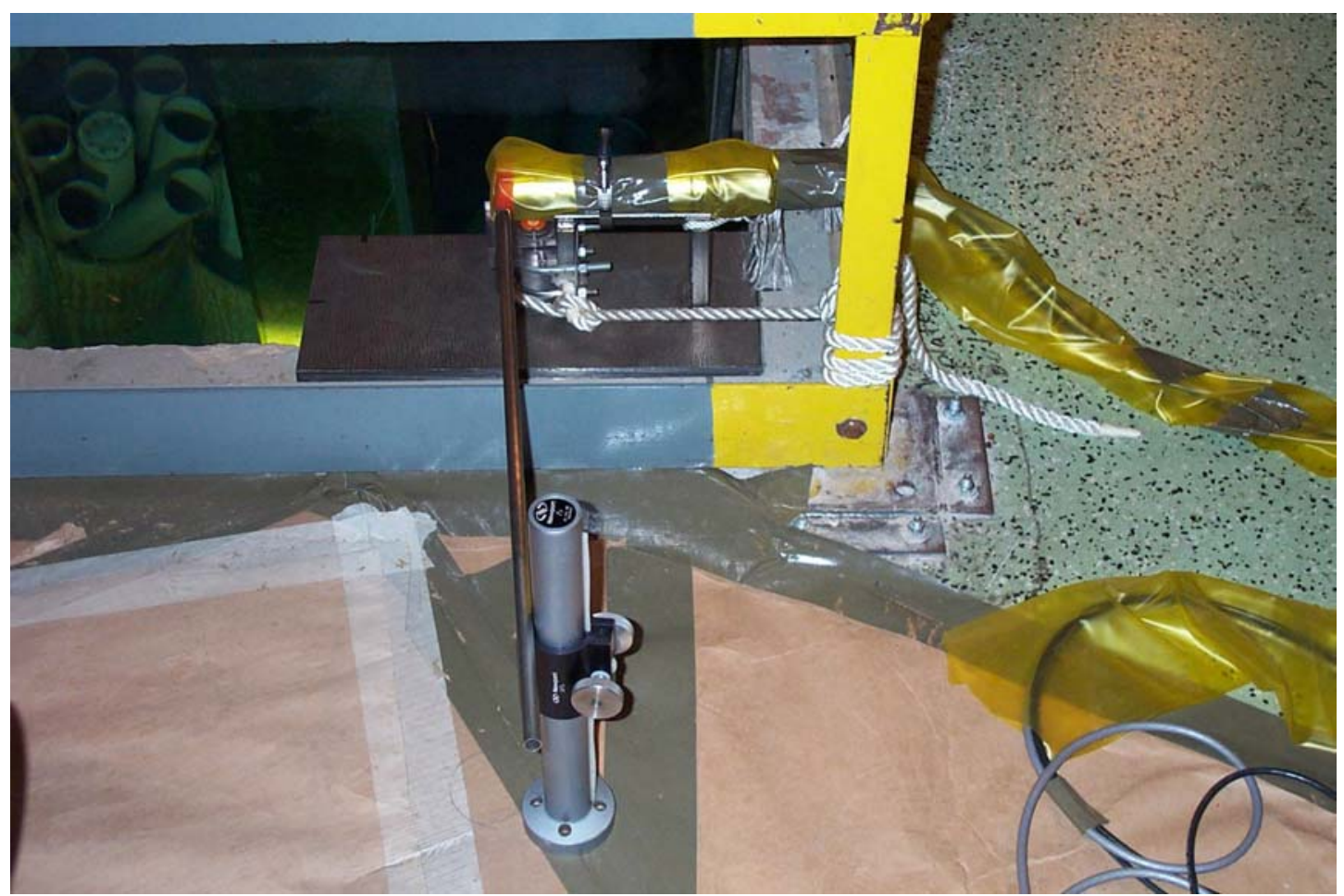

Figure 2. NaI detector arrangement for counting standard Co-60 standard source.

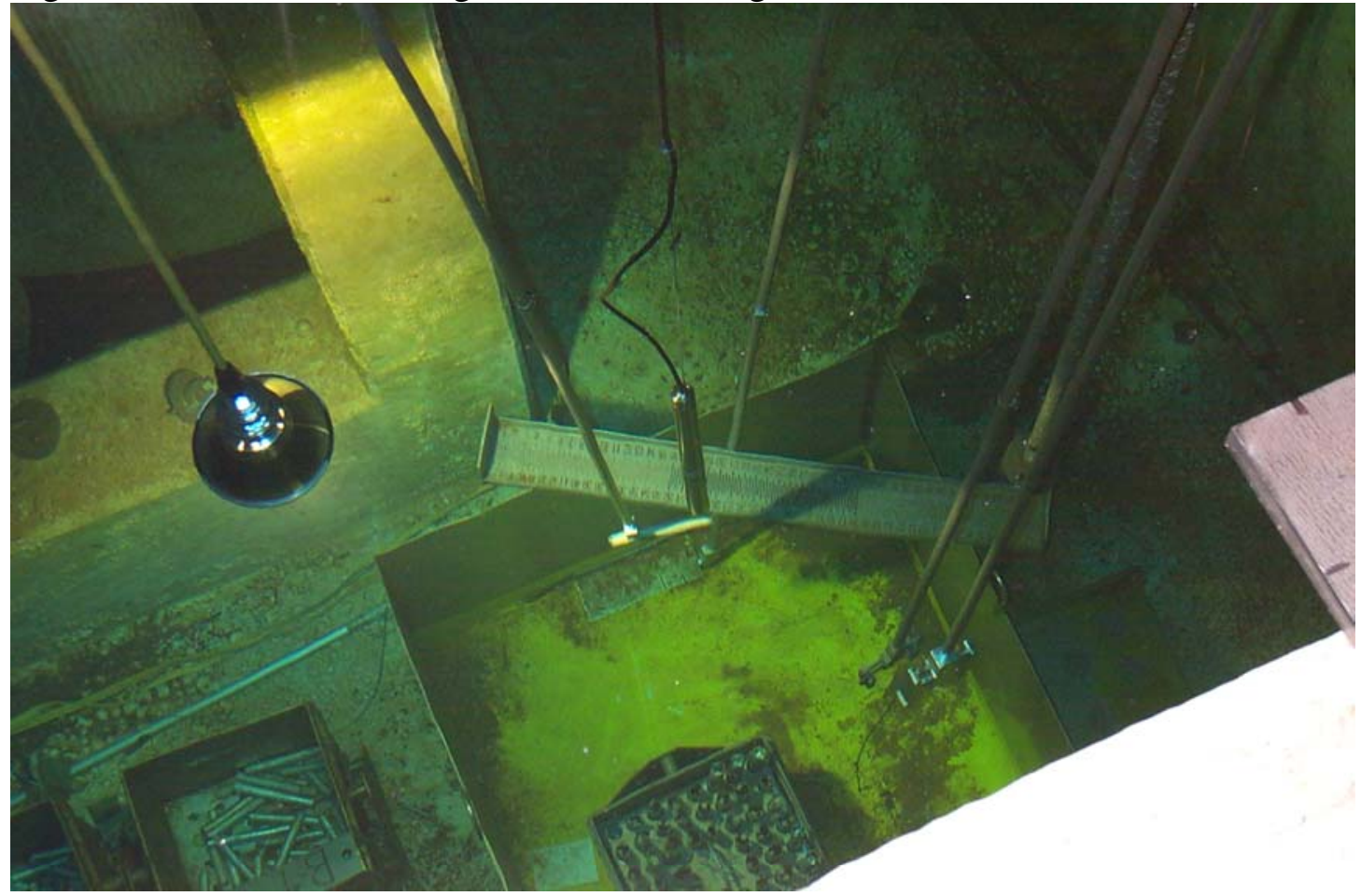

Figure 3. Underwater cobalt assay assembly showing measurement platform, $\mathrm{RO} 7$ monitor and slug bins. 
WSRC-TR-2003-00444

Revision 0

December 10, 2003

Page 11 of 41

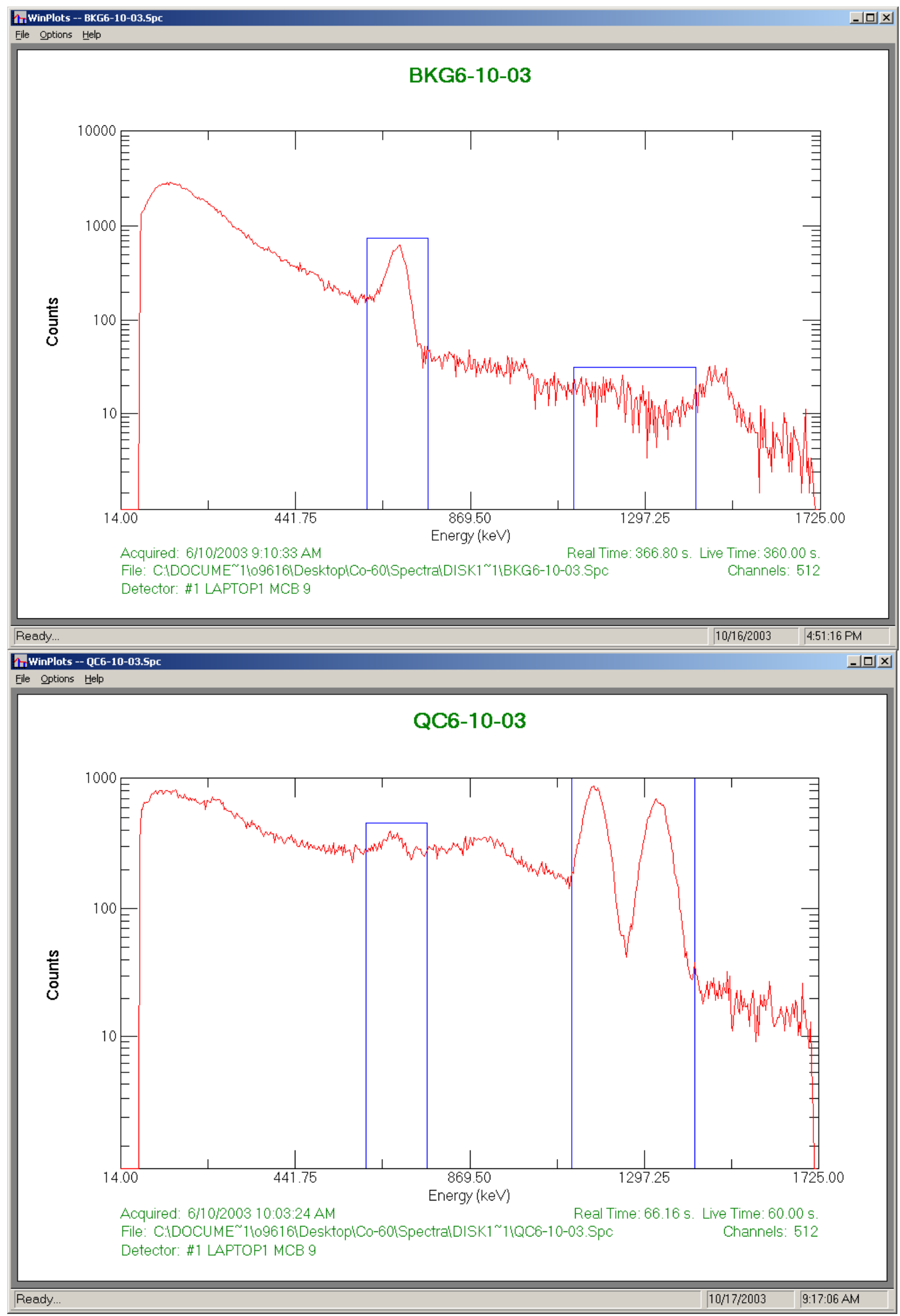

Figure 4. Typical background and Co-60 standard NaI spectra. 
WSRC-TR-2003-00444

Revision 0

December 10, 2003

Page 12 of 41

In addition to the cobalt assays, dose measurements were performed, per procedure SOP-DHS-121L, Assay of Cobalt Slugs, ${ }^{6}$ and results were recorded with the assay results. The length of each slug was measured before assays were performed, as shown in Figure 3.

\section{$\underline{\text { Instrument Setup for Curium Sampler Slugs }}$}

In order to increase the sensitivity of the measurement, the sample holder was removed from the water and the slug tray relocated from a distance of 12 " to $23 / 4$ " from the base of the collimator. The small collimators and collimator tube were removed and only the collimator pipe was used.

The 18 Curium pins were removed one at a time from the basket and assayed with the sodium idodide detector. The Co-60 in the pin was produced by irradiating a 1/16" x 1/16" piece of cobalt wire used as a neutron monitor. Since it was very difficult to position the pin properly for this measurement, the Co-60 was also obtained from RO7 dose readings of the pins by calibrating the RO7 versus assay results from previously assayed materials.

After all 18 slugs had been assayed with the NaI detector, this detector was replaced with a highresolution HPGE detector, and the pins were assayed with this detector to determine what isotopes, if any, could be identified in the slugs other than Co-60.

\section{Calibration:}

The same calibration was used as in the K Reactor assay, described in SRT-ADS-0327, and previous Co-60 slug measurements described in SRT-ADS-99-0391. For this calibration, four slugs were chosen to have different nominal values in an effort to obtain a linear relationship between Co-60 counts and activity. Analysis of the data showed that this was not possible, so the data were averaged. The basin background count rate in the ROI was subtracted from the average count and this divided by the average number of Curies/slug to obtain the conversion factor of 189 counts/two minutes/Ci for a 2" x 2" sodium iodide detector. The uncertainty in this value was determined to be $\pm 25 \%$. and this uncertainty had to be added in quadrature to the other measurement uncertainties, including counting statistics.

The slugs in L Reactor Basin are assumed to be essentially identical to those in K Reactor basin. The gamma rays seen by the detector have come from various points within the slug. Therefore, the attenuation of the gamma rays from the various portions of the slug will differ because of the differing distances traveled in the slug. Since attenuation depends upon the composition and density of the slug, if the slugs in L Basin are not identical to those in K Basin, the calibration will be in error by an unknown amount.

Both slugs and slabs were analyzed. The slugs have cobalt contained between two D-bar (halfround) pieces of aluminum, while the slabs are pieces (may be rectangular) of cobalt with cladding. Since the gamma rays from Co-60 (1.17 MeV and $1.33 \mathrm{MeV})$ are very high energy, the difference in sample attenuation is considered well within the overall uncertainties reported. 
WSRC-TR-2003-00444

Revision 0

December 10, 2003

Page 13 of 41

Since the calibration is for a certain length slug (nominally 8") and since we are only measuring gamma rays from a small portion of the sample, a correction was made for samples of length that differ from the calibration length. The slug tray distance was reduced from 12 " to $23 / 4$ " and the collimation was changed for assays of the curium sampler slugs; therefore, the same slugs were assayed at both configurations to recalibrate the system for the new distance and collimation.

Since RO7 contact measurements are more sensitive for detecting Co-60 than the assay detectors located more than eight feet from the slug, the RO7 was calibrated from previously assayed slugs for low activity measurements. The curium sampler slugs are composed primarily of aluminum by weight, as compared to the cobalt slugs that are about $48 \%$ aluminum and $52 \%$ cobalt by weight and the curium sampler slugs are contained in $~ 1 / 16$ " aluminum sleeves. Also, the cobalt was distributed uniformly throughout the slugs and the pins only contained a $1 / 16$ " x $1 / 16$ " wire (neutron monitor). Therefore, dose measurements were adjusted to account for the difference in compositions and cobalt distribution.

\section{System Quality Assurance/Quality Control:}

A background analysis was performed each day prior to sample analysis to show that essentially no Co-60 was present. A Co-60 gamma source was counted in a known geometry, as shown in Figure 2, prior to and after analysis completion to ensure that the energy calibration had not changed significantly and to verify that the counts in a designated peak agree to within the control chart limits (3-sigma).

All of the data were collected from 6/11/03 to 8/20/03. Data were kept in a logbook and spectra, representing the official data, were stored on 3 1/2" floppy disks. Over this period, fifty-three Co60 quality control checks were performed for the NaI assay systems, and four were performed for the HPGe assay system. A control chart for these checks is given in Figure 5. The last four determinations listed were for the HPGe system. Using the standard positioner shown in Figure 2, the average count ( 2 minutes) and standard deviation for the NaI QC checks were 17,440 \pm 230 , while corresponding values of 5,860 \pm 170 were obtained for the HPGe QC checks. All QC checks were within the designated 3-sigma control limits. 
WSRC-TR-2003-00444

Revision 0

December 10, 2003

Page 14 of 41

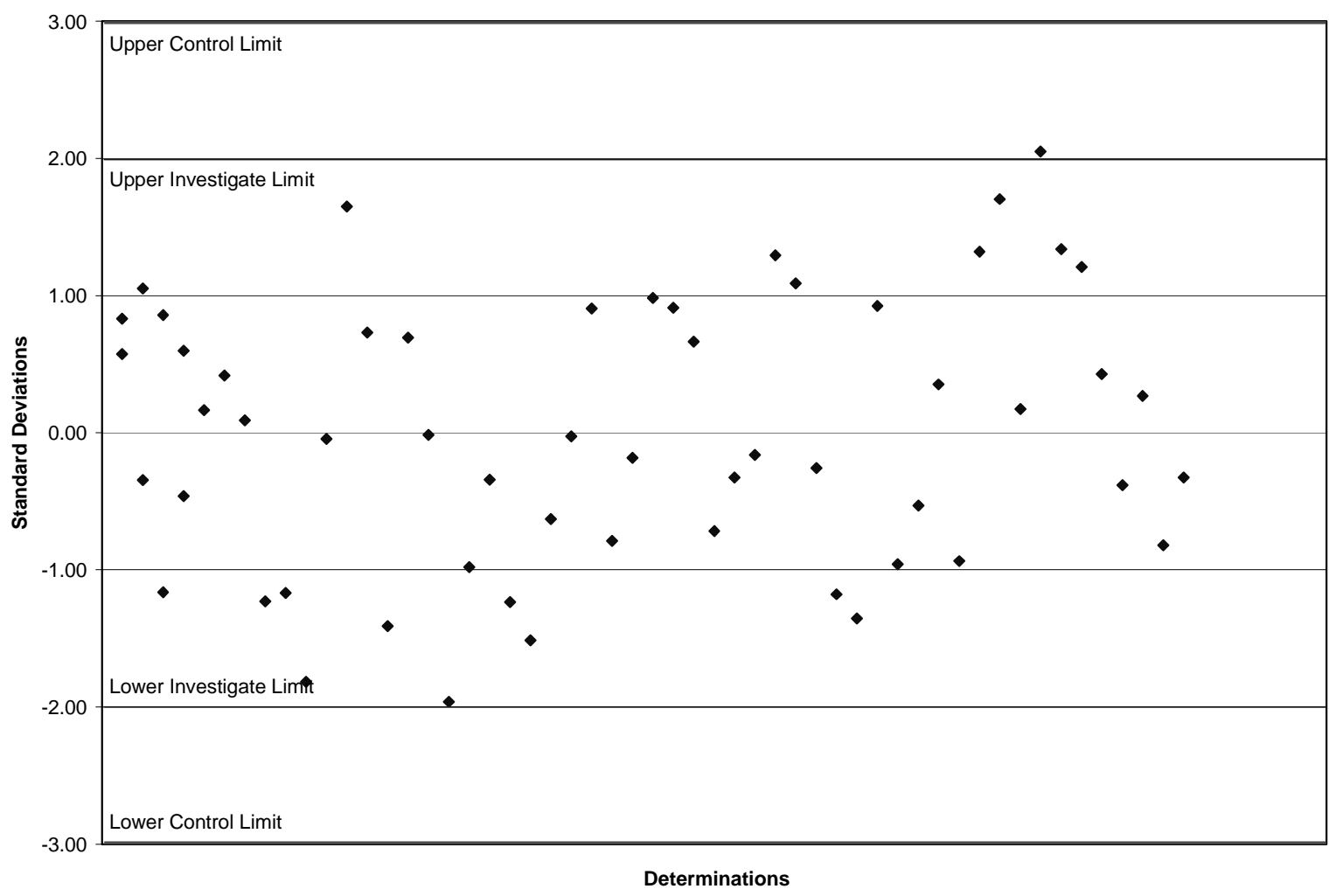

Figure 5. Control chart for Co-60 Standard Check Source (6/11/03 - 8/20/03)

\section{ANALYSIS AND RESULTS}

\section{Cobalt Slug and Slab Analysis and Results}

In order to ensure that the results from this campaign are consistent with previous measurements, nine previously analyzed slugs were reanalyzed to confirm that the present measurements are comparable to those previously done. After correcting for Co-60 decay and any differences in geometry, the total counts for the nine previously analyzed slugs was about $8 \%$ higher than expected from the results obtained in 1999. This was considered acceptable because, as stated previously, the calibration uncertainty was $\pm 25 \%$. The calibration uncertainty had to be added in quadrature to the other measurement uncertainties, primarily counting statistics for the slug measurements. For the present slug measurements with appreciable Co-60 activities, the counting statistics uncertainties were less than 5\% and did not make an appreciable contribution to the overall uncertainty.

A typical spectrum for the cobalt slugs and slabs is shown in Figure 6. The first region of interest is from Cs- 137 in the L-Basin, while the second region of interest is from the two Co-60 gamma rays at 1.17 and $1.33 \mathrm{MeV}$. The Co-60 activity in this slug was determined to be 72 curies. 
WSRC-TR-2003-00444

Revision 0

December 10, 2003

Page 15 of 41

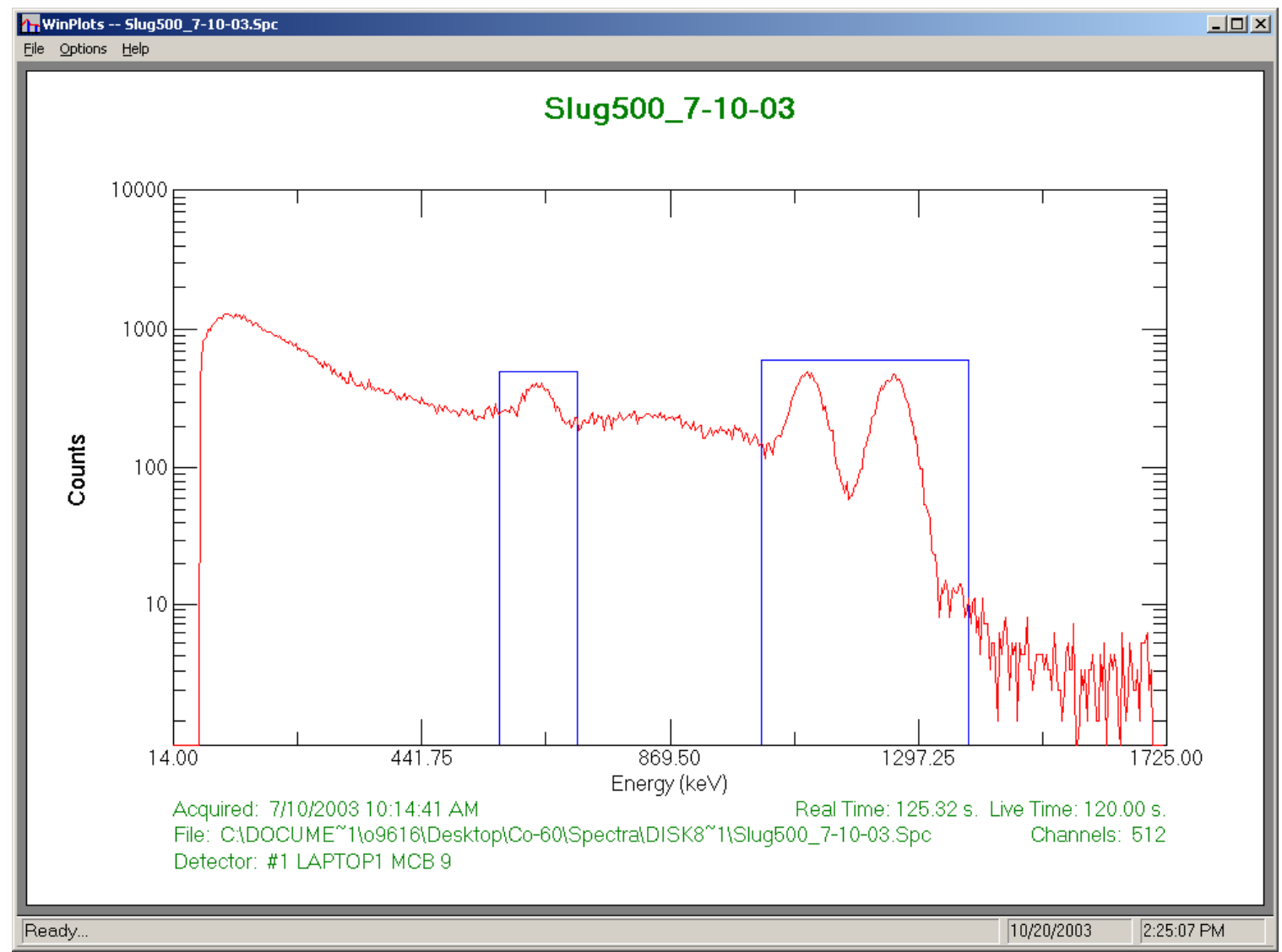

Figure 6. Typical slug spectrum with regions of interest for Cs-137 and Co-60.

All of the assay results were independently technically reviewed before the data were released.

These results are compiled in Table 1. As previously mentioned, the basin background count rate in the ROI was subtracted from the average count and this divided by the conversion factor of 189 counts/two minutes/Ci for a 2" x 2" sodium iodide detector. Analysis of 548 slugs and slabs resulted in 31,783 curies of Co-60. Each slug or slab was placed in a bin depending upon the number of curies of Co-60 measured for that item. The Co-60 curie range per bin were Bin 1( 0 curies); Bin 2 ( 0 - 50 curies); Bin 3 (50 - 100 curies); Bin 4 (100 - 150 curies); Bin 5 (150 -200 curies); Bin 6 ( $200-500$ curies) and Bin 7 (>500 curies). In some cases, based on preliminary results, items outside these ranges were placed in the bin.

As shown in Table 1, the number of slugs and slabs (items) and the curies of Co-60 for each bin were: Bin $1=156$ items, 0 curies; Bin $2=181$ items, 3957 curies; Bin $3=108$ items, 7901 curies; Bin $4=32$ items, 3959 curies; Bin $5=39$ items, 6885 curies; Bin $6=31$ items, 8387 curies and Bin7 $=1$ item, 694 curies. It is interesting to note that bins 3 through 7 contain 211 slugs representing $88 \%$ ( 27,826 curies) of the Co-60 activity, while essentially all of the remaining activity (3,957 curies) is contained in the 181 slugs in bin 2 . The total activity of all 548 assayed items summed to 31,783 curies. 
WSRC-TR-2003-00444

Revision 0

December 10, 2003

Page 16 of 41

Table 1. Curies of Co-60 in L-Area Basin Cobalt Slugs and Slabs

\begin{tabular}{|c|c|c|c|c|c|c|c|c|}
\hline Item \# & $\begin{array}{c}\text { Analysis } \\
\text { Sequence \# }\end{array}$ & Slug/Slab & $\begin{array}{l}\text { Length } \\
\text { (inches) }\end{array}$ & $\begin{array}{c}\mathrm{R} 07(\mathrm{R} / \mathrm{hr}) \\
(@ 24 ")\end{array}$ & $\begin{array}{c}\mathrm{Ci}(\mathrm{Co}-60) \\
\text { curies }\end{array}$ & Bin\# & $\mathrm{Ci} / \mathrm{Bin}$ & Items/bin \\
\hline 1 & 372 & Slug & 8 & 48.2 & 694 & 7 & 694 & 1 \\
\hline 2 & 135 & Slug & 8 & 77 & 410 & 6 & & \\
\hline 3 & 2 & Slug & 8.25 & 35 & 344 & 6 & & \\
\hline 4 & 313 & Slug & 6 & 5.6 & 339 & 6 & & \\
\hline 5 & 284 & Slug & 6 & 43.4 & 338 & 6 & & \\
\hline 6 & 154 & Slug & 8.5 & 57.5 & 324 & 6 & & \\
\hline 7 & 544 & Slug & 7.5 & 39.5 & 311 & 6 & & \\
\hline 8 & 6 & Slug & 8 & 35.4 & 293 & 6 & & \\
\hline 9 & 520 & Slug & 5.5 & 17 & 292 & 6 & & \\
\hline 10 & 5 & Slug & 8 & 35.7 & 290 & 6 & & \\
\hline 11 & 325 & Slug & 6 & 5 & 284 & 6 & & \\
\hline 12 & 330 & Slug & 6 & 5.1 & 270 & 6 & & \\
\hline 13 & 9 & Slug & 8.5 & 28.3 & 270 & 6 & & \\
\hline 14 & 341 & Slug & 6 & 5.5 & 269 & 6 & & \\
\hline 15 & 344 & Slug & 6 & 5.6 & 262 & 6 & & \\
\hline 16 & 283 & Slug & 6 & 33.4 & 262 & 6 & & \\
\hline 17 & 394 & Slug & 8.5 & 53 & 261 & 6 & & \\
\hline 18 & 339 & Slug & 6 & 5.6 & 260 & 6 & & \\
\hline 19 & 274 & Slug & 8.5 & 57.2 & 254 & 6 & & \\
\hline 20 & 7 & Slug & 8.75 & 34.3 & 254 & 6 & & \\
\hline 21 & 282 & Slug & 6 & 31.6 & 245 & 6 & & \\
\hline 22 & 286 & Slug & 6 & 38.4 & 243 & 6 & & \\
\hline 23 & 517 & Slug & 5.5 & 22.2 & 242 & 6 & & \\
\hline 24 & 543 & Slug & 9 & 23.7 & 242 & 6 & & \\
\hline 25 & 542 & Slug & 9 & 20.1 & 242 & 6 & & \\
\hline 26 & 303 & Slug & 6 & 5.6 & 242 & 6 & & \\
\hline 27 & 504 & Slug & 8.5 & 27.4 & 240 & 6 & & \\
\hline 28 & 519 & Slug & 5.5 & 23.8 & 233 & 6 & & \\
\hline 29 & 438 & Slug & 8 & 32.5 & 230 & 6 & & \\
\hline 30 & 3 & Slug & 8.5 & 27.6 & 217 & 6 & & \\
\hline 31 & 305 & Slug & 6 & 5.4 & 213 & 6 & & \\
\hline 32 & 324 & Slug & 6 & 4.5 & 212 & 6 & 8387 & 31 \\
\hline 33 & 528 & Slug & 8 & 24.4 & 200 & 5 & & \\
\hline 34 & 312 & Slug & 6 & 4.9 & 195 & 5 & & \\
\hline 35 & 70 & Slug & 8 & 29.0 & 194 & 5 & & \\
\hline 36 & 311 & Slug & 6 & 6 & 193 & 5 & & \\
\hline 37 & 321 & Slug & 6 & 5.2 & 193 & 5 & & \\
\hline 38 & 333 & Slug & 6 & 5.2 & 192 & 5 & & \\
\hline 39 & 309 & Slug & 6 & 5.8 & 192 & 5 & & \\
\hline 40 & 524 & Slug & 8 & & 188 & 5 & & \\
\hline 41 & 349 & Slug & 5.5 & 4.1 & 187 & 5 & & \\
\hline 42 & 449 & Slug & 8 & 25.6 & 186 & 5 & & \\
\hline
\end{tabular}


WSRC-TR-2003-00444

Revision 0

December 10, 2003

Page 17 of 41

Table 1. Curies of $\mathrm{Co}-60$ in L-Area Basin Cobalt Slugs and Slabs (continued)

\begin{tabular}{|c|c|c|c|c|c|c|c|c|}
\hline Item \# & $\begin{array}{c}\text { Analysis } \\
\text { Sequence \# }\end{array}$ & Slug/Slab & $\begin{array}{l}\text { Length } \\
\text { (inches) }\end{array}$ & $\begin{array}{c}\text { R07 (R/hr) } \\
\text { (@ 24") }\end{array}$ & $\begin{array}{c}\mathrm{Ci}(\mathrm{Co}-60) \\
\text { curies }\end{array}$ & Bin\# & $\mathrm{Ci} / \mathrm{Bin}$ & Items/bin \\
\hline 43 & 231 & Slug & 8 & 37.8 & 186 & 5 & & \\
\hline 44 & 257 & Slug & 8 & 41.8 & 186 & 5 & & \\
\hline 45 & 343 & Slug & 6 & 5.2 & 185 & 5 & & \\
\hline 46 & 300 & Slug & 6 & 4.9 & 184 & 5 & & \\
\hline 47 & 315 & Slug & 5.5 & 6.4 & 184 & 5 & & \\
\hline 48 & 522 & Slug & 5.5 & 18.5 & 183 & 5 & & \\
\hline 49 & 336 & Slug & 8 & 3.5 & 183 & 5 & & \\
\hline 50 & 376 & Slug & 8 & 14.6 & 178 & 5 & & \\
\hline 51 & 151 & Slug & 8 & 30 & 177 & 5 & & \\
\hline 52 & 301 & Slug & 6 & 5.8 & 177 & 5 & & \\
\hline 53 & 470 & Slug & 8 & 23.7 & 177 & 5 & & \\
\hline 54 & 331 & Slug & 6 & 4.8 & 176 & 5 & & \\
\hline 55 & 393 & Slug & 8 & 52.8 & 176 & 5 & & \\
\hline 56 & 319 & Slug & 6 & 6.1 & 175 & 5 & & \\
\hline 57 & 277 & Slug & 8.5 & 38.3 & 175 & 5 & & \\
\hline 58 & 334 & Slug & 6 & 5 & 173 & 5 & & \\
\hline 59 & 425 & Slug & 8 & 25.6 & 169 & 5 & & \\
\hline 60 & 307 & Slug & 5.5 & 6.3 & 169 & 5 & & \\
\hline 61 & 25 & Slug & 9 & 25.3 & 168 & 5 & & \\
\hline 62 & 348 & Slug & 6 & 5.3 & 164 & 5 & & \\
\hline 63 & 472 & Slug & 8 & 25 & 162 & 5 & & \\
\hline 64 & 488 & Slug & 8 & 18.3 & 161 & 5 & & \\
\hline 65 & 365 & Slug & 8 & 9 & 161 & 5 & & \\
\hline 66 & 347 & Slug & 6 & 5.6 & 160 & 5 & & \\
\hline 67 & 338 & Slug & 6 & 5.6 & 160 & 5 & & \\
\hline 68 & 362 & Slug & 6 & 6.6 & 158 & 5 & & \\
\hline 69 & 546 & Slug & 8 & 18.5 & 154 & 5 & & \\
\hline 70 & 521 & Slug & 5.5 & 14.4 & 153 & 5 & & \\
\hline 71 & 345 & Slug & 6 & 4.6 & 152 & 5 & 6885 & 39 \\
\hline 72 & 346 & Slug & 5.5 & 4.5 & 149 & 4 & & \\
\hline 73 & 508 & Slug & 8 & 18.5 & 148 & 4 & & \\
\hline 74 & 131 & Slug & 8 & 29.8 & 148 & 4 & & \\
\hline 75 & 323 & Slug & 6 & 6.7 & 144 & 4 & & \\
\hline 76 & 456 & Slug & 8 & 22 & 142 & 4 & & \\
\hline 77 & 320 & Slug & 6 & 4.2 & 142 & 4 & & \\
\hline 78 & 15 & Slug & 8.75 & 13.4 & 141 & 4 & & \\
\hline 79 & 310 & Slug & 6 & 5.5 & 131 & 4 & & \\
\hline 80 & 340 & Slug & 6 & 4.4 & 131 & 4 & & \\
\hline 81 & 281 & Slug & 6 & 19.4 & 130 & 4 & & \\
\hline 82 & 302 & Slug & 6 & 4.5 & 129 & 4 & & \\
\hline 83 & 335 & Slug & 5.5 & 4.4 & 126 & 4 & & \\
\hline 84 & 304 & Slug & 6 & 5 & 126 & 4 & & \\
\hline
\end{tabular}


WSRC-TR-2003-00444

Revision 0

December 10, 2003

Page 18 of 41

Table 1. Curies of Co-60 in L-Area Basin Cobalt Slugs and Slabs (continued)

\begin{tabular}{|c|c|c|c|c|c|c|c|c|}
\hline Item \# & $\begin{array}{c}\text { Analysis } \\
\text { Sequence \# }\end{array}$ & Slug/Slab & $\begin{array}{l}\text { Length } \\
\text { (inches) }\end{array}$ & $\begin{array}{c}\text { R07 (R/hr) } \\
\text { (@ 24") }\end{array}$ & $\begin{array}{c}\mathrm{Ci}(\mathrm{Co}-60) \\
\text { curies }\end{array}$ & Bin\# & $\mathrm{Ci} / \mathrm{Bin}$ & Items/bin \\
\hline 85 & 308 & Slug & 6 & 3 & 125 & 4 & & \\
\hline 86 & 486 & Slug & 8 & 17 & 124 & 4 & & \\
\hline 87 & 249 & Slug & 8 & 26 & 124 & 4 & & \\
\hline 88 & 489 & Slug & 8 & 16.1 & 124 & 4 & & \\
\hline 89 & 48 & Slug & 8 & 23.9 & 122 & 4 & & \\
\hline 90 & 487 & Slug & 8 & 14.7 & 120 & 4 & & \\
\hline 91 & 317 & Slug & 6 & 4.1 & 119 & 4 & & \\
\hline 92 & 318 & Slug & 6 & 3.6 & 118 & 4 & & \\
\hline 93 & 493 & Slug & 8 & 15.6 & 115 & 4 & & \\
\hline 94 & 195 & Slug & 8 & 30.8 & 114 & 4 & & \\
\hline 95 & 228 & Slug & 8 & 21.5 & 113 & 4 & & \\
\hline 96 & 342 & Slug & 6 & 4.9 & 111 & 4 & & \\
\hline 97 & 267 & Slug & 8.5 & 18.7 & 109 & 4 & & \\
\hline 98 & 136 & Slug & 9 & 21.6 & 108 & 4 & & \\
\hline 99 & 138 & Slug & 8 & 17.6 & 107 & 4 & & \\
\hline 100 & 133 & Slug & 8 & 27.9 & 107 & 4 & & \\
\hline 101 & 306 & Slug & 5.5 & 4 & 106 & 4 & & \\
\hline 102 & 506 & Slug & 8 & 12.5 & 104 & 4 & & \\
\hline 103 & 316 & Slug & 6 & 5.3 & 103 & 4 & 3959 & 32 \\
\hline 104 & 263 & Slug & 8.5 & 32.4 & 187 & 3 & & \\
\hline 105 & 516 & Slab & 13 & 8.1 & 114 & 3 & & \\
\hline 106 & 329 & Slug & 8 & 3.4 & 101 & 3 & & \\
\hline 107 & 505 & Slug & 10 & 10.9 & 100 & 3 & & \\
\hline 108 & 197 & Slug & 8 & 23.7 & 100 & 3 & & \\
\hline 109 & 374 & Slug & 8 & 6.8 & 99 & 3 & & \\
\hline 110 & 395 & Slug & 8.5 & 30.5 & 98 & 3 & & \\
\hline 111 & 295 & Slug & 6 & 4.7 & 97 & 3 & & \\
\hline 112 & 383 & Slug & 8 & 43.8 & 97 & 3 & & \\
\hline 113 & 4 & Slug & 9 & 12.4 & 96 & 3 & & \\
\hline 114 & 370 & Slug & 9 & 6.6 & 96 & 3 & & \\
\hline 115 & 314 & Slug & 6 & 3.7 & 95 & 3 & & \\
\hline 116 & 218 & Slug & 8 & 18.2 & 94 & 3 & & \\
\hline 117 & 29 & Slug & 8.5 & 10.8 & 94 & 3 & & \\
\hline 118 & 380 & Slug & 8 & 10.3 & 93 & 3 & & \\
\hline 119 & 261 & Slug & 8 & 23 & 93 & 3 & & \\
\hline 120 & 459 & Slug & 8.5 & 12.7 & 91 & 3 & & \\
\hline 121 & 357 & Slug & 8 & 4.3 & 90 & 3 & & \\
\hline 122 & 384 & Slug & 8 & 19.3 & 90 & 3 & & \\
\hline 123 & 392 & Slug & 8 & 25 & 89 & 3 & & \\
\hline 124 & 256 & Slug & 8 & 20.4 & 89 & 3 & & \\
\hline 125 & 424 & Slug & 8.5 & 14 & 89 & 3 & & \\
\hline 126 & 369 & Slug & 8 & 7.4 & 89 & 3 & & \\
\hline
\end{tabular}


WSRC-TR-2003-00444

Revision 0

December 10, 2003

Page 19 of 41

Table 1. Curies of Co-60 in L-Area Basin Cobalt Slugs and Slabs (continued)

\begin{tabular}{|c|c|c|c|c|c|c|c|c|}
\hline Item \# & $\begin{array}{c}\text { Analysis } \\
\text { Sequence \# }\end{array}$ & Slug/Slab & $\begin{array}{l}\text { Length } \\
\text { (inches) }\end{array}$ & $\begin{array}{c}\text { R07 (R/hr) } \\
\text { (@ 24") }\end{array}$ & $\begin{array}{c}\mathrm{Ci}(\mathrm{Co}-60) \\
\text { curies }\end{array}$ & Bin\# & $\mathrm{Ci} / \mathrm{Bin}$ & Items/bin \\
\hline 127 & 387 & Slug & 8 & 19.1 & 88 & 3 & & \\
\hline 128 & 469 & Slug & 8 & 13.1 & 87 & 3 & & \\
\hline 129 & 137 & Slug & 8 & 19.1 & 87 & 3 & & \\
\hline 130 & 47 & Slug & 8 & 12.8 & 85 & 3 & & \\
\hline 131 & 124 & Slug & 8 & 17.9 & 85 & 3 & & \\
\hline 132 & 100 & Slab & 13 & 8.2 & 84 & 3 & & \\
\hline 133 & 397 & Slug & 8 & 12 & 83 & 3 & & \\
\hline 134 & 1 & Slab & 13 & 5.2 & 83 & 3 & & \\
\hline 135 & 460 & Slug & 8 & 10.2 & 83 & 3 & & \\
\hline 136 & 360 & Slug & 8 & 2.9 & 82 & 3 & & \\
\hline 137 & 39 & Slug & 8.5 & 10.3 & 82 & 3 & & \\
\hline 138 & 368 & Slug & 8 & 6.3 & 82 & 3 & & \\
\hline 139 & 16 & Slug & 9 & 9 & 80 & 3 & & \\
\hline 140 & 382 & Slug & 8 & 19.6 & 79 & 3 & & \\
\hline 141 & 414 & Slug & 8 & 10 & 78 & 3 & & \\
\hline 142 & 240 & Slug & 8 & 14 & 77 & 3 & & \\
\hline 143 & 80 & Slab & 13 & 6.3 & 76 & 3 & & \\
\hline 144 & 381 & Slug & 8 & 18.2 & 76 & 3 & & \\
\hline 145 & 500 & Slug & 8 & 9.4 & 74 & 3 & & \\
\hline 146 & 386 & Slug & 8 & 14.4 & 72 & 3 & & \\
\hline 147 & 292 & Slug & 8 & 2.6 & 72 & 3 & & \\
\hline 148 & 11 & Slab & 13 & 4.7 & 72 & 3 & & \\
\hline 149 & 62 & Slab & 13 & 6.2 & 72 & 3 & & \\
\hline 150 & 77 & Slab & 13 & 6.6 & 72 & 3 & & \\
\hline 151 & 114 & Slab & 13 & 7 & 71 & 3 & & \\
\hline 152 & 12 & Slug & 9 & 8.2 & 71 & 3 & & \\
\hline 153 & 153 & Slug & 8 & 13 & 71 & 3 & & \\
\hline 154 & 95 & Slab & 13 & 6.6 & 70 & 3 & & \\
\hline 155 & 145 & Slug & 8.5 & 12.9 & 70 & 3 & & \\
\hline 156 & 96 & Slab & 13 & 7.2 & 70 & 3 & & \\
\hline 157 & 290 & Slug & 8 & 2.1 & 70 & 3 & & \\
\hline 158 & 87 & Slab & 13 & 5.9 & 69 & 3 & & \\
\hline 159 & 436 & Slug & 8 & 12.7 & 69 & 3 & & \\
\hline 160 & 252 & Slug & 8 & 17.3 & 68 & 3 & & \\
\hline 161 & 158 & Slug & 8 & 16.3 & 68 & 3 & & \\
\hline 162 & 157 & Slug & 8.5 & 19 & 68 & 3 & & \\
\hline 163 & 155 & Slug & 8 & 15.2 & 68 & 3 & & \\
\hline 164 & 88 & Slab & 13 & 8.4 & 68 & 3 & & \\
\hline 165 & 140 & Slug & 8.5 & 13.2 & 67 & 3 & & \\
\hline 166 & 53 & Slab & 13 & 5.4 & 66 & 3 & & \\
\hline 167 & 90 & Slab & 13 & 5.7 & 64 & 3 & & \\
\hline 168 & 337 & Slug & 6 & 4 & 64 & 3 & & \\
\hline
\end{tabular}


WSRC-TR-2003-00444

Revision 0

December 10, 2003

Page 20 of 41

Table 1. Curies of Co-60 in L-Area Basin Cobalt Slugs and Slabs (continued)

\begin{tabular}{|c|c|c|c|c|c|c|c|c|}
\hline Item \# & $\begin{array}{c}\text { Analysis } \\
\text { Sequence \# }\end{array}$ & Slug/Slab & $\begin{array}{c}\text { Length } \\
\text { (inches) }\end{array}$ & $\begin{array}{c}\mathrm{R} 07 \text { (R/hr) } \\
\text { (@ 24") }\end{array}$ & $\begin{array}{c}\mathrm{Ci}(\mathrm{Co}-60) \\
\text { curies } \\
\end{array}$ & Bin\# & $\mathrm{Ci} / \mathrm{Bin}$ & $\begin{array}{c}\text { Items } / \text { bi } \\
n\end{array}$ \\
\hline 169 & 65 & Slug & 8 & 12.5 & 64 & 3 & & \\
\hline 170 & 165 & Slug & 8.5 & 14.7 & 64 & 3 & & \\
\hline 171 & 171 & Slug & 8 & 17 & 63 & 3 & & \\
\hline 172 & 37 & Slug & 9 & 8.5 & 63 & 3 & & \\
\hline 173 & 52 & Slab & 13 & 6.2 & 63 & 3 & & \\
\hline 174 & 78 & Slab & 13 & 6.3 & 62 & 3 & & \\
\hline 175 & 81 & Slab & 13 & 5.4 & 62 & 3 & & \\
\hline 176 & 112 & Slab & 13 & 6 & 62 & 3 & & \\
\hline 177 & 91 & Slab & 13 & 5.4 & 61 & 3 & & \\
\hline 178 & 107 & Slab & 13 & 6.3 & 61 & 3 & & \\
\hline 179 & 86 & Slab & 13 & 7 & 61 & 3 & & \\
\hline 180 & 224 & Slug & 8 & 11.9 & 61 & 3 & & \\
\hline 181 & 84 & Slab & 12 & 6.5 & 61 & 3 & & \\
\hline 182 & 109 & Slab & 13 & 6.7 & 61 & 3 & & \\
\hline 183 & 119 & Slab & 13 & 7.4 & 60 & 3 & & \\
\hline 184 & 113 & Slab & 13 & 6.6 & 60 & 3 & & \\
\hline 185 & 68 & Slug & 8 & 9.0 & 60 & 3 & & \\
\hline 186 & 105 & Slab & 13 & 7.1 & 60 & 3 & & \\
\hline 187 & 101 & Slab & 13 & 8 & 60 & 3 & & \\
\hline 188 & 430 & Slug & 8 & 8.6 & 60 & 3 & & \\
\hline 189 & 204 & Slug & 8 & 17 & 60 & 3 & & \\
\hline 190 & 547 & Slug & 12 & 4.2 & 59 & 3 & & \\
\hline 191 & 350 & Slug & 8 & 2.5 & 58 & 3 & & \\
\hline 192 & 115 & Slab & 13 & 6.7 & 58 & 3 & & \\
\hline 193 & 260 & Slug & 8 & 12.9 & 58 & 3 & & \\
\hline 194 & 144 & Slug & 8.5 & 10.8 & 58 & 3 & & \\
\hline 195 & 111 & Slab & 13 & 6.6 & 58 & 3 & & \\
\hline 196 & 149 & Slug & 8 & 9 & 56 & 3 & & \\
\hline 197 & 515 & Slug & 8 & 8.6 & 55 & 3 & & \\
\hline 198 & 391 & Slug & 8 & 15.3 & 55 & 3 & & \\
\hline 199 & 103 & Slab & 13 & 5.1 & 55 & 3 & & \\
\hline 200 & 82 & Slab & 13 & 5.4 & 54 & 3 & & \\
\hline 201 & 378 & Slug & 8 & 6 & 54 & 3 & & \\
\hline 202 & 99 & Slab & 13 & 5.6 & 54 & 3 & & \\
\hline 203 & 170 & Slug & 8.5 & 12.1 & 54 & 3 & & \\
\hline 204 & 85 & Slab & 13 & 6.4 & 54 & 3 & & \\
\hline 205 & 110 & Slab & 13 & 7.2 & 53 & 3 & & \\
\hline 206 & 94 & Slab & 13 & 5 & 53 & 3 & & \\
\hline 207 & 417 & Slug & 8 & 8.6 & 53 & 3 & & \\
\hline 208 & 117 & Slab & 13 & 5.6 & 53 & 3 & & \\
\hline 209 & 106 & Slab & 13 & 6.3 & 52 & 3 & & \\
\hline 210 & 396 & Slug & 8 & 15.5 & 41 & 3 & & \\
\hline
\end{tabular}


WSRC-TR-2003-00444

Revision 0

December 10, 2003

Page 21 of 41

Table 1. Curies of Co-60 in L-Area Basin Cobalt Slugs and Slabs (continued)

\begin{tabular}{|c|c|c|c|c|c|c|c|c|}
\hline Item \# & $\begin{array}{c}\text { Analysis } \\
\text { Sequence \# }\end{array}$ & Slug/Slab & $\begin{array}{c}\text { Length } \\
\text { (inches) }\end{array}$ & $\begin{array}{c}\mathrm{R} 07 \text { (R/hr) } \\
\text { (@ 24") }\end{array}$ & $\begin{array}{c}\mathrm{Ci}(\mathrm{Co}-60) \\
\text { curies }\end{array}$ & Bin\# & $\mathrm{Ci} / \mathrm{Bin}$ & Items/bin \\
\hline 211 & 518 & Slug & 12.5 & 4.8 & 37 & 3 & 7901 & 108 \\
\hline 212 & 116 & Slab & 13 & 5.6 & 51 & 2 & & \\
\hline 213 & 121 & Slab & 13 & 7 & 51 & 2 & & \\
\hline 214 & 354 & Slug & 8 & 2.3 & 51 & 2 & & \\
\hline 215 & 98 & Slab & 13 & 6.1 & 50 & 2 & & \\
\hline 216 & 102 & Slab & 13 & 4.8 & 50 & 2 & & \\
\hline 217 & 108 & Slab & 13 & 6 & 49 & 2 & & \\
\hline 218 & 398 & Slug & 8 & 7.3 & 49 & 2 & & \\
\hline 219 & 19 & Slug & 9 & 8.7 & 49 & 2 & & \\
\hline 220 & 352 & Slug & 8 & 2.2 & 49 & 2 & & \\
\hline 221 & 175 & Slug & 8 & 14 & 49 & 2 & & \\
\hline 222 & 379 & Slug & 8 & 6 & 48 & 2 & & \\
\hline 223 & 451 & Slug & 8 & 6.8 & 48 & 2 & & \\
\hline 224 & 33 & Slug & 9 & 9.2 & 47 & 2 & & \\
\hline 225 & 147 & Slug & 8.5 & 12 & 47 & 2 & & \\
\hline 226 & 192 & Slug & 8 & 0 & 47 & 2 & & \\
\hline 227 & 371 & Slug & 8 & 3.4 & 47 & 2 & & \\
\hline 228 & 359 & Slug & 8 & 4.4 & 47 & 2 & & \\
\hline 229 & 20 & Slug & 9 & 7 & 47 & 2 & & \\
\hline 230 & 289 & Slug & 8 & 1.4 & 47 & 2 & & \\
\hline 231 & 74 & Slug & 8.5 & 9.7 & 46 & 2 & & \\
\hline 232 & 390 & Slug & 8 & 11.5 & 45 & 2 & & \\
\hline 233 & 14 & Slug & 9 & 5.4 & 45 & 2 & & \\
\hline 234 & 21 & Slug & 8.5 & 7.7 & 45 & 2 & & \\
\hline 235 & 373 & Slug & 8 & 4.1 & 45 & 2 & & \\
\hline 236 & 76 & Slug & 8.5 & 7.7 & 43 & 2 & & \\
\hline 237 & 457 & Slug & 8 & 6.1 & 41 & 2 & & \\
\hline 238 & 445 & Slug & 8 & 5.8 & 40 & 2 & & \\
\hline 239 & 410 & Slug & 8 & 5.8 & 40 & 2 & & \\
\hline 240 & 83 & Slab & 13 & 4.3 & 40 & 2 & & \\
\hline 241 & 97 & Slab & 13 & 6.2 & 40 & 2 & & \\
\hline 242 & 494 & Slug & 8 & 6.7 & 40 & 2 & & \\
\hline 243 & 161 & Slug & 9 & 8.6 & 39 & 2 & & \\
\hline 244 & 159 & Slug & 8 & 9 & 39 & 2 & & \\
\hline 245 & 71 & Slug & 9 & 5.5 & 39 & 2 & & \\
\hline 246 & 276 & Slug & 8 & 9.1 & 38 & 2 & & \\
\hline 247 & 167 & Slug & 8.5 & 9.1 & 38 & 2 & & \\
\hline 248 & 166 & Slug & 8 & 9.9 & 37 & 2 & & \\
\hline 249 & 134 & Slug & 8.5 & 6 & 37 & 2 & & \\
\hline 250 & 389 & Slug & 8 & 8.1 & 37 & 2 & & \\
\hline 251 & 271 & Slug & 8.25 & 6.2 & 36 & 2 & & \\
\hline 252 & 89 & Slab & 13 & 6.5 & 36 & 2 & & \\
\hline
\end{tabular}


WSRC-TR-2003-00444

Revision 0

December 10, 2003

Page 22 of 41

Table 1. Curies of Co-60 in L-Area Basin Cobalt Slugs and Slabs (continued)

\begin{tabular}{|c|c|c|c|c|c|c|c|c|}
\hline Item \# & $\begin{array}{c}\text { Analysis } \\
\text { Sequence \# }\end{array}$ & Slug/Slab & $\begin{array}{l}\text { Length } \\
\text { (inches) }\end{array}$ & $\begin{array}{c}\text { R07 (R/hr) } \\
\text { (@ 24") }\end{array}$ & $\begin{array}{c}\text { Ci(Co-60) } \\
\text { curies }\end{array}$ & Bin\# & $\mathrm{Ci} / \mathrm{Bin}$ & Items/bin \\
\hline 253 & 8 & Slug & 13 & 4.3 & 36 & 2 & & \\
\hline 254 & 238 & Slug & 8 & 8 & 36 & 2 & & \\
\hline 255 & 26 & Slug & 9 & 5.3 & 35 & 2 & & \\
\hline 256 & 128 & Slug & 8 & 6.6 & 35 & 2 & & \\
\hline 257 & 150 & Slug & 8 & 5.9 & 34 & 2 & & \\
\hline 258 & 13 & Slug & 9 & 4.3 & 34 & 2 & & \\
\hline 259 & 120 & Slab & 13 & 6 & 34 & 2 & & \\
\hline 260 & 458 & Slug & 8 & 5.5 & 34 & 2 & & \\
\hline 261 & 258 & Slug & 8 & 7 & 34 & 2 & & \\
\hline 262 & 441 & Slug & 8 & 5.1 & 34 & 2 & & \\
\hline 263 & 351 & Slug & 8 & 1.5 & 34 & 2 & & \\
\hline 264 & 225 & Slug & 8 & 6.3 & 33 & 2 & & \\
\hline 265 & 215 & Slug & 8 & 8.6 & 32 & 2 & & \\
\hline 266 & 375 & Slug & 8 & 3.5 & 32 & 2 & & \\
\hline 267 & 239 & Slug & 8 & 6.4 & 32 & 2 & & \\
\hline 268 & 184 & Slug & 8 & 9.8 & 32 & 2 & & \\
\hline 269 & 423 & Slug & 8.5 & 5.5 & 31 & 2 & & \\
\hline 270 & 44 & Slug & 8 & 0.5 & 31 & 2 & & \\
\hline 271 & 22 & Slug & 8 & 5.3 & 31 & 2 & & \\
\hline 272 & 287 & Slug & 7 & 7.5 & 29 & 2 & & \\
\hline 273 & 364 & Slug & 8 & 2.2 & 28 & 2 & & \\
\hline 274 & 122 & Slug & 8.5 & 4.7 & 28 & 2 & & \\
\hline 275 & 461 & Slug & 8 & 4.1 & 28 & 2 & & \\
\hline 276 & 356 & Slug & 8 & 1.3 & 28 & 2 & & \\
\hline 277 & 118 & Slab & 13 & 5.9 & 28 & 2 & & \\
\hline 278 & 194 & Slug & 8.5 & 6.5 & 27 & 2 & & \\
\hline 279 & 477 & Slug & 8 & 4.3 & 27 & 2 & & \\
\hline 280 & 328 & Slug & 9 & 1 & 27 & 2 & & \\
\hline 281 & 196 & Slug & 8 & 7.4 & 26 & 2 & & \\
\hline 282 & 208 & Slug & 8 & 9.3 & 26 & 2 & & \\
\hline 283 & 285 & Slug & 7 & 7.3 & 26 & 2 & & \\
\hline 284 & 139 & Slug & 8 & 4.4 & 26 & 2 & & \\
\hline 285 & 327 & Slug & 8 & 0.9 & 24 & 2 & & \\
\hline 286 & 181 & Slug & 8.5 & 4.3 & 24 & 2 & & \\
\hline 287 & 174 & Slug & 8 & 5.4 & 23 & 2 & & \\
\hline 288 & 178 & Slug & 8 & 5.4 & 23 & 2 & & \\
\hline 289 & 169 & Slug & 8 & 4.1 & 22 & 2 & & \\
\hline 290 & 126 & Slug & 8.5 & 4 & 22 & 2 & & \\
\hline 291 & 17 & Slug & 13 & 3.2 & 22 & 2 & & \\
\hline 292 & 428 & Slug & 8 & 3.8 & 21 & 2 & & \\
\hline 293 & 388 & Slug & 8 & 3.4 & 21 & 2 & & \\
\hline 294 & 200 & Slug & 8 & 5.8 & 21 & 2 & & \\
\hline
\end{tabular}


WSRC-TR-2003-00444

Revision 0

December 10, 2003

Page 23 of 41

Table 1. Curies of Co-60 in L-Area Basin Cobalt Slugs and Slabs (continued)

\begin{tabular}{|c|c|c|c|c|c|c|c|c|}
\hline Item \# & $\begin{array}{c}\text { Analysis } \\
\text { Sequence \# }\end{array}$ & Slug/Slab & $\begin{array}{l}\text { Length } \\
\text { (inches) }\end{array}$ & $\begin{array}{c}\mathrm{R} 07 \text { (R/hr) } \\
\text { (@ 24") }\end{array}$ & $\begin{array}{l}\mathrm{Ci}(\mathrm{Co}-60) \\
\text { curies }\end{array}$ & Bin\# & $\mathrm{Ci} / \mathrm{Bin}$ & Items/bin \\
\hline 295 & 255 & Slug & 8 & 5.2 & 20 & 2 & & \\
\hline 296 & 501 & Slug & 8 & 2.3 & 20 & 2 & & \\
\hline 297 & 10 & Slab & 13 & 4.9 & 20 & 2 & & \\
\hline 298 & 254 & Slug & 8 & 4.9 & 20 & 2 & & \\
\hline 299 & 55 & Slug & 8 & 2.4 & 19 & 2 & & \\
\hline 300 & 160 & Slug & 8 & 4.3 & 19 & 2 & & \\
\hline 301 & 234 & Slug & 8 & 3.8 & 19 & 2 & & \\
\hline 302 & 186 & Slug & 8 & 4.7 & 19 & 2 & & \\
\hline 303 & 447 & Slug & 8 & 3.0 & 19 & 2 & & \\
\hline 304 & 146 & Slug & 8 & 3.9 & 18 & 2 & & \\
\hline 305 & 473 & Slug & 8 & 3.3 & 18 & 2 & & \\
\hline 306 & 377 & Slug & 8 & 1.5 & 18 & 2 & & \\
\hline 307 & 272 & Slug & 8 & 3.2 & 18 & 2 & & \\
\hline 308 & 385 & Slug & 8 & 2 & 18 & 2 & & \\
\hline 309 & 429 & Slug & 8 & 3.4 & 17 & 2 & & \\
\hline 310 & 132 & Slug & 8 & 2.5 & 16 & 2 & & \\
\hline 311 & 61 & Slug & 8 & 2.4 & 16 & 2 & & \\
\hline 312 & 245 & Slug & 8 & 3.6 & 16 & 2 & & \\
\hline 313 & 237 & Slug & 8 & 3.75 & 16 & 2 & & \\
\hline 314 & 130 & Slug & 8 & 2.9 & 15 & 2 & & \\
\hline 315 & 497 & Slug & 8 & 4 & 15 & 2 & & \\
\hline 316 & 361 & Slug & 8 & 1.1 & 15 & 2 & & \\
\hline 317 & 523 & Slug & 2 & 2 & 15 & 2 & & \\
\hline 318 & 180 & Slug & 8 & 0 & 15 & 2 & & \\
\hline 319 & 444 & Slug & 8 & 2.8 & 15 & 2 & & \\
\hline 320 & 172 & Slug & 8 & 3.3 & 15 & 2 & & \\
\hline 321 & 93 & Slab & 13 & 6 & 15 & 2 & & \\
\hline 322 & 75 & Slug & 8 & 3 & 15 & 2 & & \\
\hline 323 & 296 & Slug & 8.5 & 0.5 & 15 & 2 & & \\
\hline 324 & 434 & Slug & 8 & 2.8 & 15 & 2 & & \\
\hline 325 & 437 & Slug & 8 & 2.4 & 14 & 2 & & \\
\hline 326 & 125 & Slug & 8.5 & 2.6 & 14 & 2 & & \\
\hline 327 & 211 & Slug & 8 & 4.6 & 13 & 2 & & \\
\hline 328 & 162 & Slug & 8 & 2.6 & 13 & 2 & & \\
\hline 329 & 168 & Slug & 8.5 & 3 & 13 & 2 & & \\
\hline 330 & 72 & Slug & 8 & 1.5 & 13 & 2 & & \\
\hline 331 & 220 & Slug & 8 & 2.4 & 13 & 2 & & \\
\hline 332 & 298 & Slug & 8 & 0.4 & 13 & 2 & & \\
\hline 333 & 439 & Slug & 8.5 & 2.7 & 13 & 2 & & \\
\hline 334 & 42 & Slug & 8 & 2.6 & 12 & 2 & & \\
\hline 335 & 529 & Slug & 13 & 1.3 & 12 & 2 & & \\
\hline 336 & 279 & Slug & 8.25 & 3 & 11 & 2 & & \\
\hline
\end{tabular}


WSRC-TR-2003-00444

Revision 0

December 10, 2003

Page 24 of 41

Table 1. Curies of Co-60 in L-Area Basin Cobalt Slugs and Slabs (continued)

\begin{tabular}{|c|c|c|c|c|c|c|c|c|}
\hline Item \# & $\begin{array}{c}\text { Analysis } \\
\text { Sequence \# }\end{array}$ & Slug/Slab & $\begin{array}{l}\text { Length } \\
\text { (inches) }\end{array}$ & $\begin{array}{c}\mathrm{R} 07 \text { (R/hr) } \\
\text { (@ 24") }\end{array}$ & $\begin{array}{c}\mathrm{Ci}(\mathrm{Co}-60) \\
\text { curies }\end{array}$ & Bin\# & $\mathrm{Ci} / \mathrm{Bin}$ & Items/bin \\
\hline 337 & 35 & Slug & 8 & 1.7 & 11 & 2 & & \\
\hline 338 & 253 & Slug & 8 & 1.9 & 9 & 2 & & \\
\hline 339 & 104 & Slab & 13 & 7 & 9 & 2 & & \\
\hline 340 & 545 & Slug & 7.5 & 0.2 & 9 & 2 & & \\
\hline 341 & 431 & Slug & 8 & 1.8 & 9 & 2 & & \\
\hline 342 & 471 & Slug & 8 & 2.2 & 9 & 2 & & \\
\hline 343 & 450 & Slug & 8 & 2 & 9 & 2 & & \\
\hline 344 & 467 & Slug & 8 & 1.8 & 9 & 2 & & \\
\hline 345 & 152 & Slug & 8 & 1.4 & 8 & 2 & & \\
\hline 346 & 454 & Slug & 8 & 2.1 & 8 & 2 & & \\
\hline 347 & 142 & Slug & 8 & 1.2 & 8 & 2 & & \\
\hline 348 & 60 & Slug & 8 & 1.2 & 8 & 2 & & \\
\hline 349 & 455 & Slug & 8 & 1.9 & 8 & 2 & & \\
\hline 350 & 266 & Slug & 8.5 & 1.4 & 8 & 2 & & \\
\hline 351 & 511 & Slug & 8 & 1.3 & 8 & 2 & & \\
\hline 352 & 297 & Slug & 8 & 0.2 & 7 & 2 & & \\
\hline 353 & 244 & Slug & 8 & 1.6 & 7 & 2 & & \\
\hline 354 & 248 & Slug & 8 & 1.8 & 7 & 2 & & \\
\hline 355 & 164 & Slug & 8 & 1.2 & 7 & 2 & & \\
\hline 356 & 24 & Slug & 8 & 1.3 & 7 & 2 & & \\
\hline 357 & 221 & Slug & 8 & 1.6 & 7 & 2 & & \\
\hline 358 & 427 & Slug & 8 & 1.7 & 7 & 2 & & \\
\hline 359 & 38 & Slug & 8.5 & 1 & 6 & 2 & & \\
\hline 360 & 420 & Slug & 8 & 1.7 & 6 & 2 & & \\
\hline 361 & 191 & Slug & 8 & 1.4 & 6 & 2 & & \\
\hline 362 & 188 & Slug & 8 & 1.2 & 6 & 2 & & \\
\hline 363 & 31 & Slug & 8 & 1.1 & 6 & 2 & & \\
\hline 364 & 355 & Slug & 8 & 0.3 & 5 & 2 & & \\
\hline 365 & 478 & Slug & 8 & 1.5 & 5 & 2 & & \\
\hline 366 & 163 & Slug & 8 & 1.3 & 5 & 2 & & \\
\hline 367 & 490 & Slug & 8 & 2 & 5 & 2 & & \\
\hline 368 & 498 & Slug & 8 & 2 & 4 & 2 & & \\
\hline 369 & 141 & Slug & 8 & 0.5 & 4 & 2 & & \\
\hline 370 & 251 & Slug & 8 & 0.9 & 4 & 2 & & \\
\hline 371 & 57 & Slug & 8 & 0.3 & 3 & 2 & & \\
\hline 372 & 183 & Slug & 8 & 0.5 & 3 & 2 & & \\
\hline 373 & 45 & Slug & 8 & 0.5 & 3 & 2 & & \\
\hline 374 & 411 & Slug & 8 & 1.2 & 3 & 2 & & \\
\hline 375 & 479 & Slug & 8 & 1.3 & 3 & 2 & & \\
\hline 376 & 79 & Slug & 8 & 0.4 & 2 & 2 & & \\
\hline 377 & 59 & Slug & 8 & 0.5 & 2 & 2 & & \\
\hline 378 & 322 & Slug & 6 & 0.1 & 2 & 2 & & \\
\hline
\end{tabular}


WSRC-TR-2003-00444

Revision 0

December 10, 2003

Page 25 of 41

Table 1. Curies of Co-60 in L-Area Basin Cobalt Slugs and Slabs (continued)

\begin{tabular}{|c|c|c|c|c|c|c|c|c|}
\hline Item \# & $\begin{array}{c}\text { Analysis } \\
\text { Sequence \# }\end{array}$ & Slug/Slab & $\begin{array}{l}\text { Length } \\
\text { (inches) }\end{array}$ & $\begin{array}{l}\text { R07 (R/hr) } \\
\text { (@ 24") }\end{array}$ & $\begin{array}{c}\mathrm{Ci}(\mathrm{Co}-60) \\
\text { curies }\end{array}$ & Bin\# & Ci/Bin & Items/bin \\
\hline 379 & 408 & Slug & 8 & 1 & 2 & 2 & & \\
\hline 380 & 433 & Slug & 8 & 1.2 & 2 & 2 & & \\
\hline 381 & 227 & Slug & 8 & 0.7 & 2 & 2 & & \\
\hline 382 & 216 & Slug & 8 & 1 & 1 & 2 & & \\
\hline 383 & 40 & Slug & 8 & 0 & 1 & 2 & & \\
\hline 384 & 226 & Slug & 8 & 0.4 & 1 & 2 & & \\
\hline 385 & 299 & Slug & 8 & 0.1 & 1 & 2 & & \\
\hline 386 & 210 & Slug & 8 & 0.3 & 1 & 2 & & \\
\hline 387 & 485 & Slug & 8 & 1.5 & 1 & 2 & & \\
\hline 388 & 435 & Slug & 8 & 1.3 & 0.5 & 2 & & \\
\hline 389 & 482 & Slug & 8 & 1.5 & 0.3 & 2 & & \\
\hline 390 & 69 & Slug & 8 & 0.1 & 0.2 & 2 & & \\
\hline 391 & 422 & Slug & 8 & 0.7 & 0.1 & 2 & & \\
\hline 392 & 43 & Slug & 8.5 & 0 & 0.1 & 2 & 3957 & 181 \\
\hline 393 & 413 & Slug & 8 & 0.7 & 0 & 1 & & \\
\hline 394 & 18 & Slug & 8.5 & 0.02 & 0 & 1 & & \\
\hline 395 & 23 & Slug & 8.5 & 0 & 0 & 1 & & \\
\hline 396 & 27 & Slug & 8.75 & 0 & 0 & 1 & & \\
\hline 397 & 28 & Slug & 9 & 0.2 & 0 & 1 & & \\
\hline 398 & 30 & Slug & 8 & 0 & 0 & 1 & & \\
\hline 399 & 32 & Slug & 8 & 0 & 0 & 1 & & \\
\hline 400 & 34 & Slug & 8.5 & 0.1 & 0 & 1 & & \\
\hline 401 & 36 & Slug & 8 & 0 & 0 & 1 & & \\
\hline 402 & 41 & Slug & 8 & 0.01 & 0 & 1 & & \\
\hline 403 & 46 & Slug & 9 & 0 & 0 & 1 & & \\
\hline 404 & 49 & Slug & 8 & 0.0 & 0 & 1 & & \\
\hline 405 & 50 & Slug & 8 & 0.0 & 0 & 1 & & \\
\hline 406 & 51 & Slug & 8 & 0.0 & 0 & 1 & & \\
\hline 407 & 54 & Slug & 8 & 0.0 & 0 & 1 & & \\
\hline 408 & 56 & Slug & 8 & 0.2 & 0 & 1 & & \\
\hline 409 & 58 & Slug & 8 & 0.1 & 0 & 1 & & \\
\hline 410 & 63 & Slug & 8 & 0.0 & 0 & 1 & & \\
\hline 411 & 64 & Slug & 8 & 0.0 & 0 & 1 & & \\
\hline 412 & 66 & Slug & 8 & 0.1 & 0 & 1 & & \\
\hline 413 & 67 & Slug & 9 & 0.1 & 0 & 1 & & \\
\hline 414 & 73 & Slug & 8 & 0.0 & 0 & 1 & & \\
\hline 415 & 92 & Slug & 8 & 0 & 0 & 1 & & \\
\hline 416 & 123 & Slug & 8.5 & 0.1 & 0 & 1 & & \\
\hline 417 & 127 & Slug & 9 & 0.1 & 0 & 1 & & \\
\hline 418 & 129 & Slug & 8 & 0.1 & 0 & 1 & & \\
\hline 419 & 143 & Slug & 8.5 & 0.2 & 0 & 1 & & \\
\hline 420 & 148 & Slug & 8.5 & 0.1 & 0 & 1 & & \\
\hline
\end{tabular}

Table 1. Curies of Co-60 in L-Area Basin Cobalt Slugs and Slabs (continued) 
WSRC-TR-2003-00444

Revision 0

December 10, 2003

Page 26 of 41

\begin{tabular}{|c|c|c|c|c|c|c|c|c|}
\hline Item \# & $\begin{array}{c}\text { Analysis } \\
\text { Sequence \# }\end{array}$ & Slug/Slab & $\begin{array}{c}\text { Length } \\
\text { (inches) }\end{array}$ & $\begin{array}{c}\text { R07 (R/hr) } \\
\text { (@ 24") }\end{array}$ & $\begin{array}{c}\text { Ci(Co-60) } \\
\text { curies }\end{array}$ & Bin\# & Ci/Bin & Items/bin \\
\hline 421 & 156 & Slug & 8 & 0.2 & 0 & 1 & & \\
422 & 173 & Slug & 8 & 0 & 0 & 1 & \\
423 & 176 & Slug & 8 & 0 & 0 & 1 & \\
424 & 177 & Slug & 8 & 0.1 & 0 & 1 & \\
425 & 179 & Slug & 8 & 0 & 0 & 1 & \\
426 & 182 & Slug & 8 & 0 & 0 & 1 & \\
427 & 185 & Slug & 8 & 0 & 0 & 1 & \\
428 & 187 & Slug & 8 & 0 & 0 & 1 & \\
429 & 189 & Slug & 8 & 0 & 0 & 1 & \\
430 & 190 & Slug & 8 & 0 & 0 & 1 & \\
431 & 193 & Slug & 8 & 0 & 0 & 1 & \\
432 & 198 & Slug & 8.5 & 0 & 0 & 1 & \\
433 & 199 & Slug & 8 & 0.1 & 0 & 1 & \\
434 & 201 & Slug & 8.5 & 0 & 0 & 1 & \\
435 & 202 & Slug & 8 & 0 & 0 & 1 & \\
436 & 203 & Slug & 8.5 & 0 & 0 & 1 & \\
437 & 205 & Slug & 8 & 0 & 0 & 1 & \\
438 & 206 & Slug & 8 & 0.3 & 0 & 1 & \\
439 & 207 & Slug & 8 & 0.1 & 0 & 1 & \\
440 & 209 & Slug & 8 & 0 & 0 & 1 & \\
441 & 212 & Slug & 8 & 0 & 0 & 1 & \\
442 & 213 & Slug & 8 & 0 & 0 & 1 & \\
443 & 214 & Slug & 9 & 0 & 0 & 1 & \\
444 & 217 & Slug & 8 & 0.1 & 0 & 1 & \\
445 & 219 & Slug & 8 & 0.1 & 0 & 1 & \\
446 & 222 & Slug & 8 & 0 & 0 & 1 & \\
447 & 223 & Slug & 8 & 0.4 & 0 & 1 & \\
448 & 229 & Slug & 8 & 0 & 0 & 1 & \\
449 & 230 & Slug & 8 & 0 & 0 & 1 & \\
450 & 232 & Slug & 8 & 0 & 0 & 1 & \\
451 & 233 & Slug & 8 & 0 & 0 & 1 & \\
452 & 235 & Slug & 8 & 0 & 0 & 1 & \\
453 & 236 & Slug & 8 & 0.2 & 0 & 1 & \\
454 & 241 & Slug & 8 & 0 & 0 & 1 & \\
455 & 242 & Slug & 8 & 0 & 0 & 1 & \\
456 & 243 & Slug & 8 & 0 & 0 & 1 & \\
457 & 246 & Slug & 8 & 0 & 0 & 1 & \\
458 & 247 & Slug & 8 & 0 & 0 & 1 & \\
459 & 250 & Slug & 8 & 0 & 0 & 1 & \\
460 & 259 & Slug & 8 & 0 & 0 & 1 & \\
461 & 262 & Slug & 8 & 0 & 0 & 1 & \\
462 & 264 & Slug & 8.25 & 0 & 0 & 1 & \\
& & & & & & & \\
\end{tabular}


WSRC-TR-2003-00444

Revision 0

December 10, 2003

Page 27 of 41

Table 1. Curies of Co-60 in L-Area Basin Cobalt Slugs and Slabs (continued)

\begin{tabular}{|c|c|c|c|c|c|c|c|c|}
\hline Item \# & $\begin{array}{c}\text { Analysis } \\
\text { Sequence \# }\end{array}$ & Slug/Slab & $\begin{array}{l}\text { Length } \\
\text { (inches) }\end{array}$ & $\begin{array}{c}\text { R07 (R/hr) } \\
\text { (@ 24") }\end{array}$ & $\begin{array}{c}\mathrm{Ci}(\mathrm{Co}-60) \\
\text { curies }\end{array}$ & Bin\# & $\mathrm{Ci} / \mathrm{Bin}$ & Items/bin \\
\hline 463 & 265 & Slug & 8.25 & 0 & 0 & 1 & & \\
\hline 464 & 268 & Slug & 8.25 & 0 & 0 & 1 & & \\
\hline 465 & 269 & Slug & 8.25 & 0.1 & 0 & 1 & & \\
\hline 466 & 270 & Slug & 8.25 & 0.1 & 0 & 1 & & \\
\hline 467 & 273 & Slug & 8.25 & 0.1 & 0 & 1 & & \\
\hline 468 & 275 & Slug & 8.25 & 0.1 & 0 & 1 & & \\
\hline 469 & 278 & Slug & 8.25 & 0.1 & 0 & 1 & & \\
\hline 470 & 280 & Slug & 8.25 & 0.1 & 0 & 1 & & \\
\hline 471 & 288 & Slug & 8 & 0.1 & 0 & 1 & & \\
\hline 472 & 291 & Slug & 8 & 0 & 0 & 1 & & \\
\hline 473 & 293 & Slug & 8 & 0 & 0 & 1 & & \\
\hline 474 & 294 & Slug & 8 & 0 & 0 & 1 & & \\
\hline 475 & 326 & Slug & 8 & 0 & 0 & 1 & & \\
\hline 476 & 332 & Slug & 8.5 & 0.1 & 0 & 1 & & \\
\hline 477 & 353 & Slug & 8.5 & 0.1 & 0 & 1 & & \\
\hline 478 & 358 & Slug & 6 & 0.1 & 0 & 1 & & \\
\hline 479 & 363 & Slug & 8 & 0.1 & 0 & 1 & & \\
\hline 480 & 366 & Slug & 8 & 0.2 & 0 & 1 & & \\
\hline 481 & 367 & Slug & 8 & 1.5 & 0 & 1 & & \\
\hline 482 & 399 & Slug & 8 & 0.6 & 0 & 1 & & \\
\hline 483 & 400 & Slug & 8 & 0.5 & 0 & 1 & & \\
\hline 484 & 401 & Slug & 8.5 & 0.5 & 0 & 1 & & \\
\hline 485 & 402 & Slug & 8.5 & 0.6 & 0 & 1 & & \\
\hline 486 & 403 & Slug & 8 & 0.6 & 0 & 1 & & \\
\hline 487 & 404 & Slug & 8 & 0.6 & 0 & 1 & & \\
\hline 488 & 405 & Slug & 8 & 0.6 & 0 & 1 & & \\
\hline 489 & 406 & Slug & 8 & 0.7 & 0 & 1 & & \\
\hline 490 & 407 & Slug & 8 & 0.7 & 0 & 1 & & \\
\hline 491 & 409 & Slug & 8 & 0.7 & 0 & 1 & & \\
\hline 492 & 412 & Slug & 8 & 0.7 & 0 & 1 & & \\
\hline 493 & 415 & Slug & 8.5 & 0.7 & 0 & 1 & & \\
\hline 494 & 416 & Slug & 8 & 0.7 & 0 & 1 & & \\
\hline 495 & 418 & Slug & 8 & 0.8 & 0 & 1 & & \\
\hline 496 & 419 & Slug & 8.5 & 0.8 & 0 & 1 & & \\
\hline 497 & 421 & Slug & 8 & 0.7 & 0 & 1 & & \\
\hline 498 & 426 & Slug & 8.5 & 0.8 & 0 & 1 & & \\
\hline 499 & 432 & Slug & 8 & 1 & 0 & 1 & & \\
\hline 500 & 440 & Slug & 8 & 0.9 & 0 & 1 & & \\
\hline 501 & 442 & Slug & 8 & 0.8 & 0 & 1 & & \\
\hline 502 & 443 & Slug & 8 & 0.9 & 0 & 1 & & \\
\hline 503 & 446 & Slug & 8 & 0.8 & 0 & 1 & & \\
\hline 504 & 448 & Slug & 8 & 0.9 & 0 & 1 & & \\
\hline
\end{tabular}


WSRC-TR-2003-00444

Revision 0

December 10, 2003

Page 28 of 41

Table 1. Curies of Co-60 in L-Area Basin Cobalt Slugs and Slabs (continued)

\begin{tabular}{|c|c|c|c|c|c|c|c|c|}
\hline Item \# & $\begin{array}{c}\text { Analysis } \\
\text { Sequence \# }\end{array}$ & Slug/Slab & $\begin{array}{c}\text { Length } \\
\text { (inches) }\end{array}$ & $\begin{array}{c}\text { R07 (R/hr) } \\
\text { (@ 24") }\end{array}$ & $\begin{array}{c}\text { Ci(Co-60) } \\
\text { curies }\end{array}$ & Bin\# & Ci/Bin & Items/bin \\
\hline 505 & 452 & Slug & 8 & 0.5 & 0 & 1 & & \\
506 & 453 & Slug & 8 & 1 & 0 & 1 & \\
507 & 462 & Slug & 8.5 & 0.8 & 0 & 1 & \\
508 & 463 & Slug & 8 & 0.9 & 0 & 1 & \\
509 & 464 & Slug & 8.5 & 0.9 & 0 & 1 & \\
510 & 465 & Slug & 8 & 0.9 & 0 & 1 & \\
511 & 466 & Slug & 8 & 0.9 & 0 & 1 & \\
512 & 468 & Slug & 8 & 0.9 & 0 & 1 & \\
513 & 474 & Slug & 8 & 0.9 & 0 & 1 & \\
514 & 475 & Slug & 8 & 0.9 & 0 & 1 & \\
515 & 476 & Slug & 8 & 0.8 & 0 & 1 & \\
516 & 480 & Slug & 8 & 1 & 0 & 1 & \\
517 & 481 & Slug & 8 & 0.9 & 0 & 1 & \\
518 & 483 & Slug & 8 & 1.3 & 0 & 1 & \\
519 & 484 & Slug & 8 & 1.4 & 0 & 1 & \\
520 & 491 & Slug & 8 & 1.4 & 0 & 1 & \\
521 & 492 & Slug & 8 & 1.5 & 0 & 1 & \\
522 & 495 & Slug & 8 & 1.5 & 0 & 1 & \\
523 & 496 & Slug & 8 & 1.5 & 0 & 1 & \\
524 & 499 & Slug & 8 & 0.1 & 0 & 1 & \\
525 & 502 & Slug & 8 & 0 & 0 & 1 & \\
526 & 503 & Slug & 8 & 0 & 0 & 1 & \\
527 & 507 & Slug & 8 & 0.1 & 0 & 1 & \\
528 & 509 & Slug & 8 & 0 & 0 & 1 & \\
529 & 510 & Slug & 8 & 0 & 0 & 1 & \\
530 & 512 & Slug & 8 & 0.1 & 0 & 1 & \\
531 & 513 & Slug & 8 & 0.2 & 0 & 1 & \\
532 & 514 & Slug & 8 & 0.1 & 0 & 1 & \\
533 & 525 & Slug & 7.5 & 0.2 & 0 & 1 & \\
534 & 526 & Slug & 11 & 0.2 & 0 & 1 & \\
535 & 527 & Slug & 11.5 & 0.2 & 0 & 1 & \\
536 & 530 & Slug & 12 & 0 & 0 & 1 & \\
537 & 531 & Slug & 12 & 0 & 0 & 1 & \\
538 & 532 & Slug & 6 & 0 & 0 & 1 & \\
539 & 533 & Slug & 1 & 0 & 0 & 1 & \\
540 & 534 & Slug & 1 & 0 & 0 & 1 & \\
541 & 535 & Slug & 2 & 0 & 0 & 1 & \\
542 & 536 & Slug & 1 & 0 & 0 & 1 & \\
543 & 537 & Slug & 1 & 0 & 0 & 1 & \\
544 & 538 & Slug & 2 & 0.1 & 0 & 1 & \\
545 & 539 & Slug & 1 & 0 & 0 & 1 & \\
546 & 540 & Slug & 3 & 0 & 0 & 1 & \\
& & & & & & & \\
& & & 0.9 & \\
\end{tabular}


Table 1. Curies of Co-60 in L-Area Basin Cobalt Slugs and Slabs (continued)

\begin{tabular}{|c|c|c|c|c|c|c|c|c|}
\hline Item \# & $\begin{array}{c}\text { Analysis } \\
\text { Sequence \# }\end{array}$ & Slug/Slab & $\begin{array}{c}\text { Length } \\
\text { (inches) })\end{array}$ & $\begin{array}{c}\mathrm{R} 07 \\
(\mathrm{R} / \mathrm{hr}) \\
(@ 24 ")\end{array}$ & $\begin{array}{c}\text { Ci(Co-60) } \\
\text { (uries }\end{array}$ & Bin\# & Ci/Bin & Items/bin \\
\hline 547 & 541 & Slug & 3 & 0 & 0 & 1 & \\
548 & 548 & Slug & 4 & 0 & 0 & 1 & $\mathbf{0}$ & $\mathbf{1 5 6}$ \\
\hline
\end{tabular}

\section{Curium Sampler Slug Analysis and Results (NaI detector/RO7 Monitor)}

The curium sampler slugs have been stored in the basin for over thirty years. They originally contained a small piece of cobalt wire (1/16" x 1/16") to act as a neutron monitor, and 100 milligrams of $\mathrm{Pu}-239$ to convert to $\mathrm{Cm}-244$. When the slugs were irradiated, the neutron flux converted some of the cobalt into Co-60, which has decayed since the irradiation. By determining the amount of Co-60 produced for a known irradiation time, the neutron flux was determined and the amount of original $\mathrm{Pu}-239$ remaining was determined. ${ }^{7}$

After the slug tray was moved from 12 " to $23 / 4$ " and the collimators were removed, routine NaI assays (2-min counts) were done on all the curium sampler slugs, and a 50,000-second count was done on selected slug \#0654. Figure 7 shows the spectrum of the 50,000-second count. Except for Cs-137 from the basin water and a detectable peak for Co-60, no other peaks were detected above background.

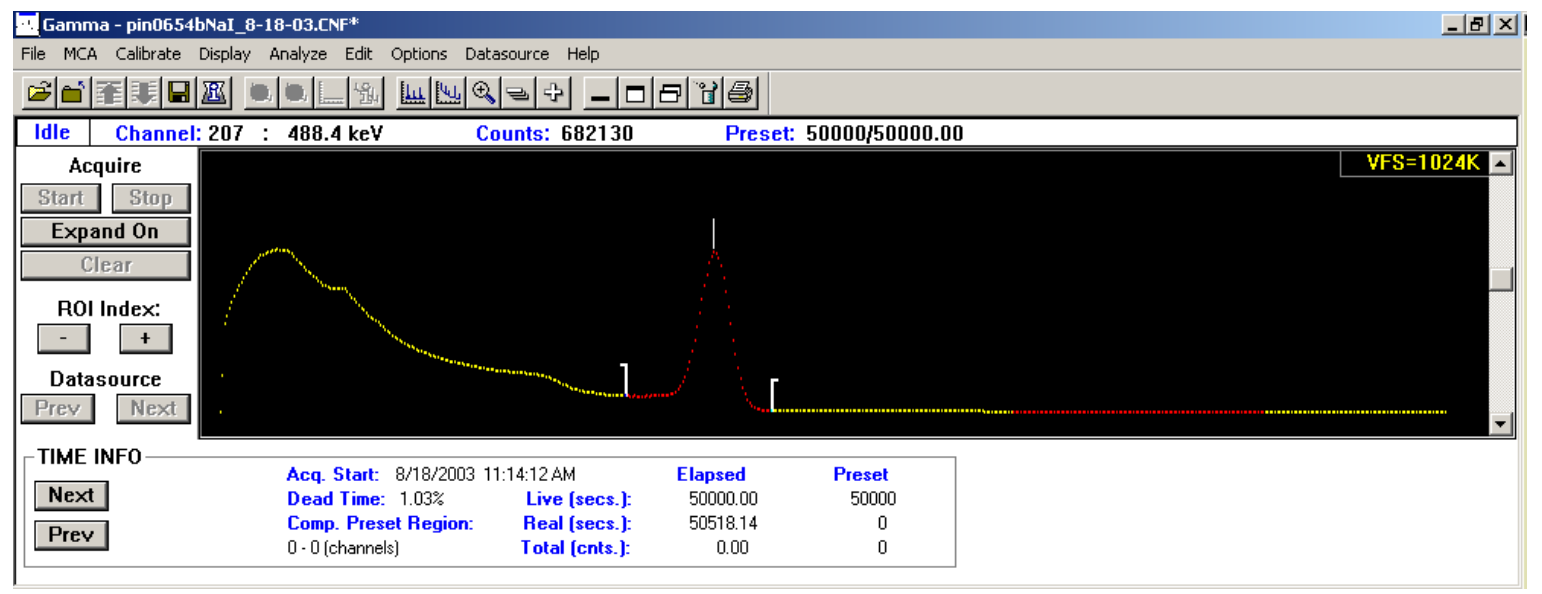

Figure 7. NaI count $(50,000 \mathrm{sec})$ at collimator tray distance of $23 / 4$ " with collimators removed. 
Since the RO7 dose monitor (on contact) was the most sensitive instrument, it was calibrated with a previously analyzed cobalt slug and used for the Co-60 determination (described below). ${ }^{8}$

\section{System Calibration for Movement of Slug Tray from 12" to $23 / 4$ " and remove collimators}

NaI Assay - Slugs w/ collimators and tray @ 12"

Slug Counts time (s)

Cal \#3 $7259 \quad 600$

NaI Assay - Slugs w/o collimators and tray @ 23/4"

Slug Counts time (s)

Cal \#3 $394230 \quad 120$

Geometry Correction $=(394230 / 120) /(7259 / 600)=272$

Geometry Correction $=272$ (used to measure cobalt below in different geometry)

(The distance correction of moving the tray without moving the collimators was determined to be 5.8; therefore, the correction for removing the collimators is calculated to be $(272 / 5.8)=47$.)

\section{Calibration of RO7 Radiation Monitor for Contact Measurements}

$\begin{array}{lccccc} & \text { NaI } & & \text { RO7 (R/Hr) } & \text { Measured } & \\ \text { Slug } & \text { Counts (Co-60) } & \text { Length (inches) } & \text { contact } & \text { Ci(Co-60) } & (\mathbf{R} / \mathbf{H r}) / \mathbf{C i} \\ \text { cal\#2 } & 72252 & 8 & 74.4 & 1.405 & \mathbf{5 3}\end{array}$

3. Measured values in $\mathrm{R} / \mathrm{hr}$ of Co-60 per Curium Sampler Slug (Pin) on contact

$\begin{array}{ll}\text { PIN } & \text { (R/H } \\ 632 & 2.6 \\ 615 & 2.1 \\ 633 & 2.6 \\ 640 & 2.4 \\ 625 & 2.2 \\ 641 & 2.5 \\ 636 & 2.5 \\ 618 & 2.3 \\ 639 & 2.4 \\ 616 & 2.5 \\ 601 & 2.3 \\ 650 & 2.3\end{array}$


WSRC-TR-2003-00444

Revision 0

December 10, 2003

Page 31 of 41

$\begin{array}{ll}637 & 2.4 \\ 635 & 2.5 \\ 653 & 2.6 \\ 648 & 2.6 \\ 621 & 2.6\end{array}$

$\mathrm{AVE}=2.4 \mathrm{R} / \mathrm{Hr}$

4. Determination of Curium Sampler Slug (pin) R07 detection efficiency versus Cobalt Slug detector efficiency ${ }^{9}$

Corrected

Microshield Water Att Microshield Corr Microshield Eff. Ratio

Slug Det Eff Slug value Slug Det Eff Pin Det Eff (Pin Det Eff / Slug Det Eff)

$3.19 \mathrm{E}+05 \times \quad 0.95=3.03 \mathrm{E}+05 \quad 1.09 \mathrm{E}+06 \quad \mathbf{3 . 6 0 E}+\mathbf{0 0}$

5. Determination of the average curies of Co-60 per Curium Sampler Slug (pin)

Ci Co-60/pin (8/4/2003) $=($ Pin R/Hr $) /(($ Slug R/Hr $/$ Eff. Ratio $))$

Pin $(\mathrm{R} / \mathrm{Hr}) \quad \mathrm{R} / \mathrm{Hr} / \mathrm{Ci}$ (slug) $\quad$ Eff. Ratio

$2.4 \quad 53 \quad 3.60 \mathrm{E}+00$

Ci Co-60/pin (8/4/2003)

0.0126

\section{Cobalt Produced in PIN Irradiation}

Volume of wire $=\pi \times \mathrm{r}^{2} \times \mathrm{L}$; where $\mathrm{r}=$ radius, $\mathrm{L}=$ length

Volume of wire $\left(\mathrm{cm}^{3}\right)=3.1416 \mathrm{x}(1 / 32)^{2} \mathrm{in}^{2} \mathrm{x}(1 / 16)$ in $\mathrm{x}(2.54) 3 \mathrm{~cm}^{3} / \mathrm{in}^{3}$

Volume of wire $(\mathrm{cm} 3)=3.14 \mathrm{E}-03$

Target Nuclei $=\mathrm{V} \times \rho \times \mathrm{N}_{\mathrm{Av}} / \mathrm{A}$; where $\rho=$ density, $\mathrm{N}_{\mathrm{Av}}=$ Avagadro's Number, $\mathrm{A}=$ atomic wt Target Nuclei $=\left(3.14 \mathrm{E}-03 \mathrm{~cm}^{3} \times 8.9 \mathrm{~g} / \mathrm{cm}^{3} \times 6.02 \mathrm{E}+23\right.$ atoms $) / 58.93 \mathrm{~g}$

Target Nuclei $(\mathrm{N})=2.86 \mathrm{E}+20$

$\mathrm{Ci}($ assay $)=\mathbf{2 . 0 2} \mathrm{Ci}$ produced on 12/19/1964 $\quad(0.0126 \mathrm{Ci} 8 / 4 / 03)$

7. Per report TC 1-1361, the curium sampler slugs were irradiated for 0.55 years and the flux is calculated as follows:

Co-60 activity $=(\sigma \times \mathrm{N} \times \phi / 3.7 \mathrm{E}+10)\left(1-\mathrm{e}^{-\lambda t}\right)$; where $\sigma=$ thermal neutron cross section, $\phi=$ thermal neutron flux, $\lambda=$ Co-60 decay constant

$2.02=\left(37 \mathrm{E}-24 \mathrm{~cm}^{-1} \times 2.86 \mathrm{E}+20\right.$ nuclei $\left.\times \phi \mathrm{n} / \mathrm{cm}^{2} / \mathrm{sec} / 3.7 \mathrm{E}+10 \mathrm{dps} / \mathrm{Ci}\right)\left(1-\mathrm{e}^{(-0.693 \times 0.55 / 5.27)}\right)$

flux $=1.01 \mathrm{E}+14 \mathrm{n} / \mathrm{cm} 2 / \mathrm{sec}$ 
WSRC-TR-2003-00444

Revision 0

December 10, 2003

Page 32 of 41

8. From this flux and using the graphs in report TA 1-1361, the activities obtained for the 18 pins (total grams $\mathbf{P u}-239=0.1$ grams/pin $\times 18$ pins) are given in Table 2.

Table 2. Activities produced from irradiation of 18 curium sampler slugs.

Nuclide g/g Pu-239 gPu-239 half-life (yr) decay factor grams 8/4/03 Ci 8/4/03

$\begin{array}{lllllll}\text { Pu-238 } & 5.0 \mathrm{E}-06 & 1.8 \mathrm{E}+00 & 8.775 \mathrm{E}+01 & 7.37 \mathrm{E}-01 & 6.6 \mathrm{E}-06 & \mathbf{1 . 1 E}-04 \\ \text { Pu-239 } & 2.7 \mathrm{E}-01 & 1.8 \mathrm{E}+00 & 2.413 \mathrm{E}+04 & 9.99 \mathrm{E}-01 & 4.9 \mathrm{E}-01 & \mathbf{3 . 0 E}-02 \\ \text { Pu-240 } & 2.2 \mathrm{E}-01 & 1.8 \mathrm{E}+00 & 6.569 \mathrm{E}+03 & 9.96 \mathrm{E}-0 & 3.9 \mathrm{E}-01 & \mathbf{8 . 9 E}-02 \\ \text { Pu-241 } & 6.0 \mathrm{E}-02 & 1.8 \mathrm{E}+0 & 1.44 \mathrm{E}+01 & 1.56 \mathrm{E}-01 & 1.7 \mathrm{E}-02 & \mathbf{1 . 7 E}+\mathbf{0 0} \\ \mathbf{P u}-242 & 2.0 \mathrm{E}-02 & 1.8 \mathrm{E}+00 & 3.758 \mathrm{E}+05 & 1.00 \mathrm{E}+00 & 3.6 \mathrm{E}-02 & \mathbf{1 . 4 E - 0 4} \\ \text { Am-241 } & 4.5 \mathrm{E}-04 & 1.8 \mathrm{E}+00 & 4.322 \mathrm{E}+02 & 9.40 \mathrm{E}-01 & 7.6 \mathrm{E}-04 & \mathbf{2 . 6 E}-03 \\ \text { Am-243 } & 1.3 \mathrm{E}-03 & 1.8 \mathrm{E}+00 & 7.380 \mathrm{E}+03 & 9.96 \mathrm{E}-01 & 2.3 \mathrm{E}-03 & \mathbf{4 . 6 E - 0 4} \\ \mathbf{C m}-242 & 2.5 \mathrm{E}-04 & 1.8 \mathrm{E}+00 & 4.468 \mathrm{E}-01 & 9.55 \mathrm{E}-27 & 4.3 \mathrm{E}-30 & \mathbf{8 . 6 E}-27 \\ \mathbf{C m}-244 & 1.1 \mathrm{E}-04 & 1.8 \mathrm{E}+00 & 1.811 \mathrm{E}+01 & 2.28 \mathrm{E}-01 & 4.5 \mathrm{E}-05 & \mathbf{3 . 7 E - 0 1}\end{array}$

Measurement Uncertainty $=$ slug calibration uncertainty + RO7 calibration uncertainty + geometry correction

Measurement Uncertainty $=100 * \operatorname{SQRT}\left((0.25)^{2}+(0.20)^{2}+(0.15)^{2}\right)=\mathbf{3 5 \%}$

\section{Curium Sampler Slug Analysis and Results (HPGe detector)}

Since a high purity germanium (HPGe) detector has much better resolution than a NaI detector, 2min counts were done on all the curium sampler slugs with the HPGe detector at a collimator tray distance of $23 / 4$ " with the collimators removed. No nuclides except Cs- 137 from the basin water were detected. A 50,000 sec count was done on sampler slug labeled 0618 (spectrum shown in Figure 8) and in addition to Cs-137 a very small Co-60 peak was detected. Although some Co-60 was detected, it was impossible to position the curium slug in the collimator tray such that the exact position of the 1/16" x 1/16" cobalt wire was known. The wire was known to be approximately in the center of the slug, but its position within the slug, which affects the attenuation, also was not known. Therefore, this arrangement was not deemed to be reliable for the Co-60 measurement. 
The primary reason that this detector system was used was to look for any nuclides present. No other nuclides were detected below the Cs-137 (661.65 keV) peak shown because of the high Compton background. In addition to Cs-137, the only other discernable peaks detected were for the nuclides Eu-154 (723.4; 873.5; 1004.9;1274.3 keV), Co-60 (1173.2; $1332.5 \mathrm{keV})$ and K-40 $(1460.6 \mathrm{keV})$.

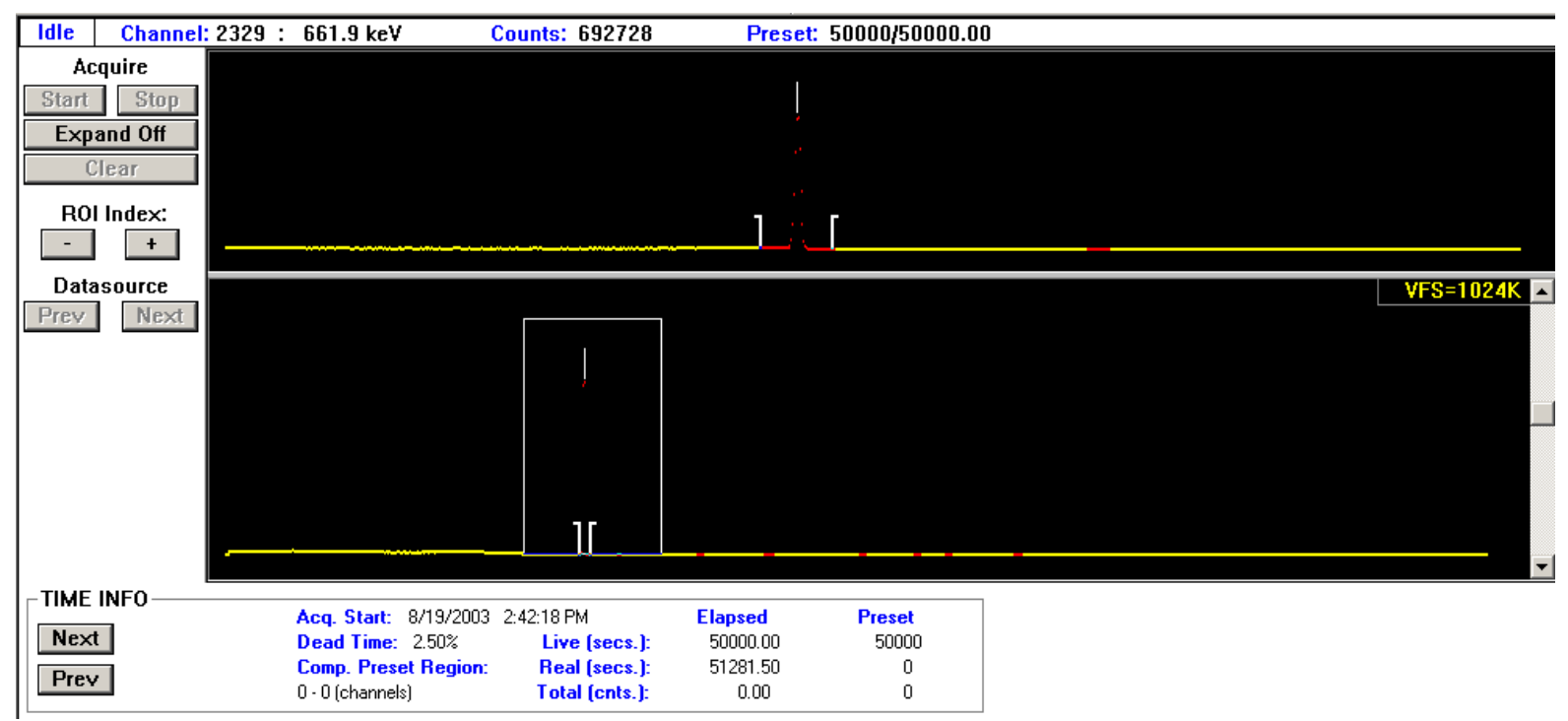

Figure 8. HPGe 50,000 sec count of curium sampler slug 0618; Cs-137 peak seen in top window.

\section{CONCLUSIONS}

Using a sodium iodide detector and multichannel analyzer system and an underwater collimator assembly, the Co-60 concentrations were determined for 548 L-Reactor Disassembly Basin cobalt slugs and slabs and 18 curium sampler slugs. The total activity of all of the 548 assayed slugs and slabs (items) summed to 31,783 curies. No Co-60 was detected for 156 items, while 180 had $0-$ 50 curies; 108 had 50 - 100 curies; 32 had 100 - 150 curies; 40 had 150 - 200 curies; 31 had 200 500 curies, and 1 had greater than 500 curies.

The amount of Co-60 in the curium sampler slugs was determined by calibrating an RO7 dose monitor with a slug of known activity. A geometry correction was made for the curium sampler slug cobalt distribution (1/16" x 1/16' wire) compared to the cobalt slug geometry ( 8 " rod). From the Co-60 of the curium sampler slugs, the irradiation flux was determined for the known irradiation time. The amounts of Pu-238,239,240,241,242; Am-241,243; and Cm-242,244 produced were then obtained based on the original amount of $\mathrm{Pu}-239$ irradiated. The curium sampler slugs were analyzed with a high purity germanium detector (overnight count). In addition to Cs-137 from the basin water, the only other discernable peaks were for Co-60, Eu-154 and K-40. 
WSRC-TR-2003-00444

Revision 0

December 10, 2003

Page 34 of 41

\section{REFERENCES}

1. F. S. Moore and Saleem Salaymeh, SRT-ADS-99-0327, Co-60 Assay Values of Co-60 Slugs in K Reactor Disassembly Basin, 8/10/99.

2. Frank Moore and Saleem Salaymeh, SRT-ADS-99-0391, Co-60 Assay Values of Co-60 Slugs in L Reactor Disassembly Area, 9/13/99.

3. Frank Moore and Saleem Salaymeh, SRT-ADS-99-0453, Assay of Miscellaneous Slugs in L Reactor Storage Basin, 11/3/99.

4. SOP-DHS-117-L, Rev. 0, Receipt of Cobalt in 8-Ton SRL Cask-Disassembly, 6/03.

5. Hilley, J.R., Smith, J.A., Nelson, E.C., Curium-244 Production Program, TA 1-1361, 4/21/64.

6. SOP-DHS-121-L, Rev. 0, Assay of Cobalt Slugs, 6/03.

7. MacLeod, S.M., Curium-244 Production Program, TC 1-1361, 10/25/65.

8. Casella, V.R., Determinations of Radionuclides in L-Area Curium Sampler Slugs (Pins), GGLC-A-00116, 9/16/03.

9. Microshield v5.03 (5.03-00075), Grove Engineering, Rockville, Maryland, 10/96. 
WSRC-TR-2003-00444

Revision 0

December 10, 2003

Page 35 of 41

\section{Appendix 1. Qualification Plan for Characterizing Cobalt Slugs in L-Basin}

\section{Qualification Plan for Characterizing Cobalt Slugs in L-Basin (SRT-ADS-2003-0-303)}

\section{Purpose:}

This methodology provides the requirements for analysis and reporting of Co-60 concentrations in SRS L-Basin cobalt slugs.

These slugs were stored in the basin for many years. They were the input slugs for various irradiation campaigns, fuel assembly spacers, and the irradiated slugs resulting from various campaigns. The Co slugs were irradiated in the early 1970 s to an activity of up to approximately $50-60,000 \mathrm{Ci} / \mathrm{slug}$. Decay corrected to the present time, this yields potentially up to $1 \mathrm{KCi} / \mathrm{slug}$. The most cost effective way to shield a source of this magnitude is to use the basin water in which the slugs are stored as the shield, while keeping the gamma detector above the water. Very little information exists on the isotopic content of the slugs.

\section{Scope:}

This task is part of the SRTC/ADS support being provided to Special Nuclear Fuels to develop and implement a non-destructive analysis (NDA) method that can be used to measure the Co-60 in SRS LBasin cobalt slugs.

\section{Responsibilities:}

a. Task Manager: the task manager is responsible for ensuring that the task activities are adequately controlled and documented.

b. Task Leader (CTF): the task $\mathrm{CTF}$ is responsible for ensuring that the requirements of this methodology are followed and complied with. The task CTF may verbally delegate activities to team members.

c. Task Scientist: task scientists are responsible to follow the requirements of this methodology.

Procedure:

\section{a. Instrument Setup:}

i. An air filled collimator has been designed, as described in SRT-ADS-99-0327, to allow a small pencil of gamma radiation from the slug to reach the detector, a 2"x 2" NaI crystal. Eleven feet of basin water provided the gamma ray shielding. A tray to hold the slug was placed below the lower end of the collimator. 
WSRC-TR-2003-00444

Revision 0

December 10, 2003

Page 36 of 41

ii. A portable multichannel analyzer (MCA) and associated electronics will be used for data acquisition and analysis. Data will be stored on floppy disks for subsequent review and analysis and permanent retention.

ii. The gamma ray spectrum from Co-60 consists of two gamma rays, one at $1.17 \mathrm{MeV}$ and the other at $1.33 \mathrm{MeV}$. A "region of interest" (ROI) will be defined around these two gamma rays in the spectrum, and the number of counts in this region summed by the MCA software. This provided the data necessary to assay the slugs. A typical gamma ray spectrum is shown in SRTADS-99-0391. The two prominent Co-60 peaks can be seen with the ROI markers around them, and a small Cs-137 peak is also seen in the basin water.

iii. Per procedure SOP-DHS-121-L, Assay of Cobalt Slugs, RO-7 readings will be taken of the slug and recorded.

b. Calibration:

i. The same calibration will be used as in the K Reactor assay, described in SRT-ADS-0327, and previous Co-60 slug measurements described in SRT-ADS-99-0391. Four slugs were chosen to have different nominal values in an effort to obtain a linear relationship between counts and activity. Analysis of the data showed that this was not possible, so the data were averaged. The basin background count rate in the ROI was subtracted from the average count and this divided by the average number of Curies/slug to obtain the conversion factor of 189089 counts/two minutes/ KCi. The uncertainty in this value is $+/-25 \%$ and this uncertainty must be added in quadrature to the other measurement uncertainties, including counting statistics.

The slugs in L Basin are assumed to be essentially identical to those in K Reactor basin. The gamma rays seen by the detector have come from various points within the slug. Therefore the attenuation of the gamma rays from the various portions of the slug will differ because of the differing distances traveled in the slug. Since attenuation depends upon the composition and density of the slug, if the slugs in L Basin are not identical to those in K Basin, the calibration will be in error by an unknown amount.

ii. The Task CTF and Task Manager will review all NDA results and reports to verify that there are no features present that will make the slugs unsuitable for analysis. The task CTF and Task Manager will initial and date the NDA reports to indicate acceptance of the NDA results.

c. System Quality Assurance/Quality Control:

i. A background analysis will be performed each day prior to sample analysis and approved by the Task CTF or Task Manager or Task Scientist.

ii. A gamma source will be counted in a known geometry prior to analysis and after analysis completion to ensure that the energy calibration has not changed significantly and to verify that the counts in a designated peak agree to within the previously determined control chart limits (3-sigma). This source check must be approved by the Task CTF or Task Manager or Task Scientist. If the source checks 
WSRC-TR-2003-00444

Revision 0

December 10, 2003

Page 37 of 41

are not within the control chart limits, the samples must be re-assayed or a reason that the sample(s) are not re-assayed must be documented in a final report.

iii. All data will be kept in a notebook and spectra will be stored on 31/2" floppy disks.

iv. Both slugs and slabs will be analyzed. The slugs have cobalt contained between two D-bar (half-round) pieces of metal (may be aluminum), while the slabs are pieces (may be rectangular) of cobalt with cladding. Since the gamma rays from Co-60 (1.17 MeV and 1.33 $\mathrm{MeV}$ ) are very high energy, the difference in sample attenuation is considered well within the overall uncertainties reported.

v. Since the calibration is for a certain length slug (nominally 8") and since we are only measuring gamma rays from a portion of the sample, a correction must be made for samples of length that differ from the calibration length.

vi. In order to ensure that the results from this campaign are consistent with previous measurements, previously analyzed slugs will be reanalyzed to confirm that the present measurements are comparable to those previously done.

\section{Final Report:}

a. The results and conclusions of this investigation will be documented by a final report that will be prepared by the Task Manager. The report will be peer reviewed by the task team members and/or designated subject matter experts and will be approved by the task manager prior to issue.

b. The report will be provided to the L-Area Project Manager as part of the SRTC supporting work to this task.

\section{References:}

SRT-ADS-99-0327 Co-60 Assay Values of Co-60 Slugs in K Reactor Disassembly Basin, F. S. Moore and Saleem Salaymeh, Aug.10, 1999.

SRT-ADS-99-0391 Co-60 Assay Values of Co-60 Slugs in L Reactor Disassembly Area, Frank Moore and Saleem Salaymeh, Sep.13, 1999.

SRT-ADS-99-0453 Assay of Miscellaneous Slugs in L Reactor Storage Basin, Frank Moore and Saleem Salaymeh, Nov.3, 1999.

SOP-DHS-121-L Assay of Cobalt Slugs, June, 2003. 
WSRC-TR-2003-00444

Revision 0

December 10, 2003

Page 38 of 41

\section{Appendix 2. Microshield calculation for curium sampler slug geometry correction.}

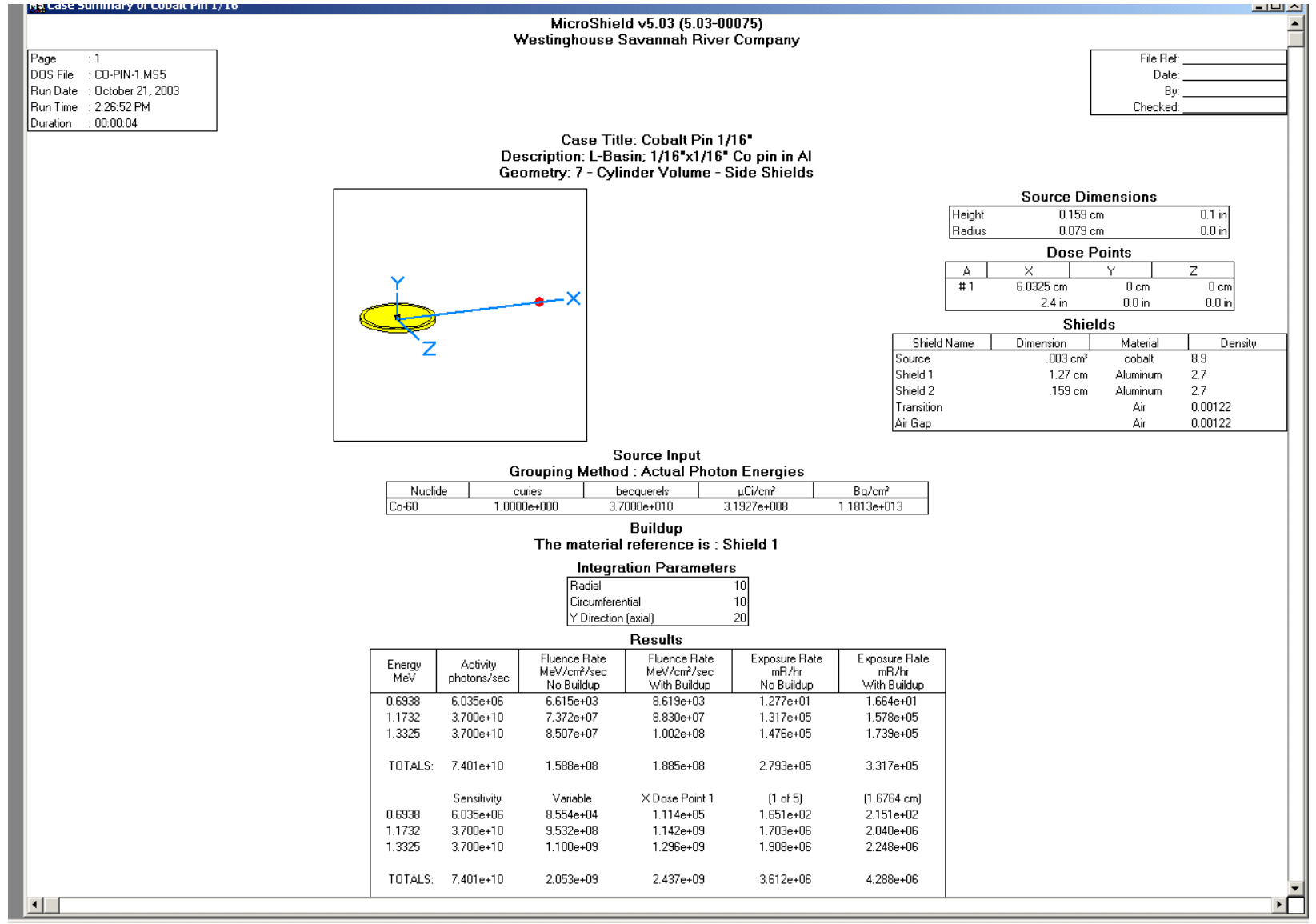


WSRC-TR-2003-00444

Revision 0

December 10, 2003

Page 39 of 41

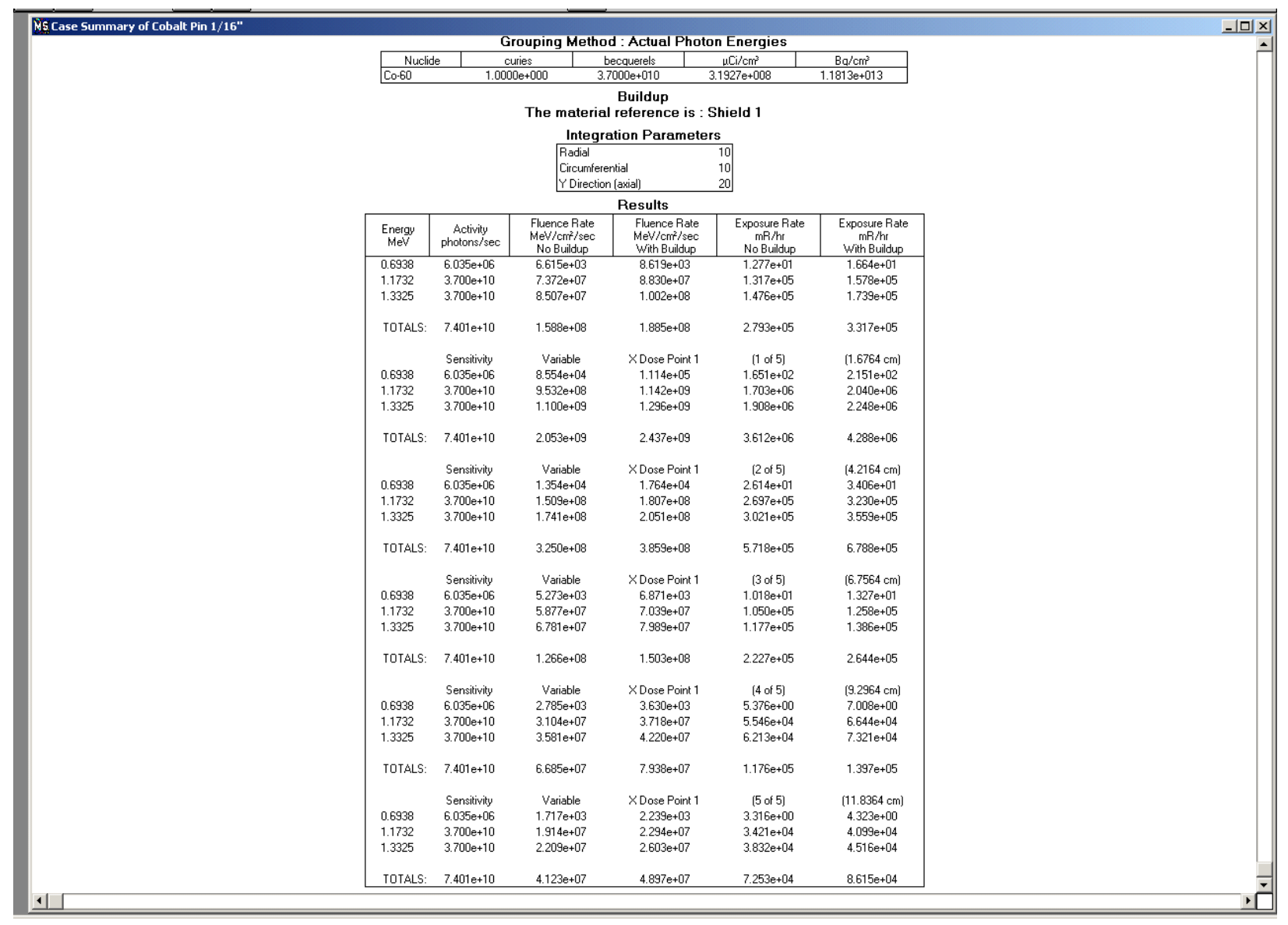


WSRC-TR-2003-00444

Revision 0

December 10, 2003

Page 40 of 41

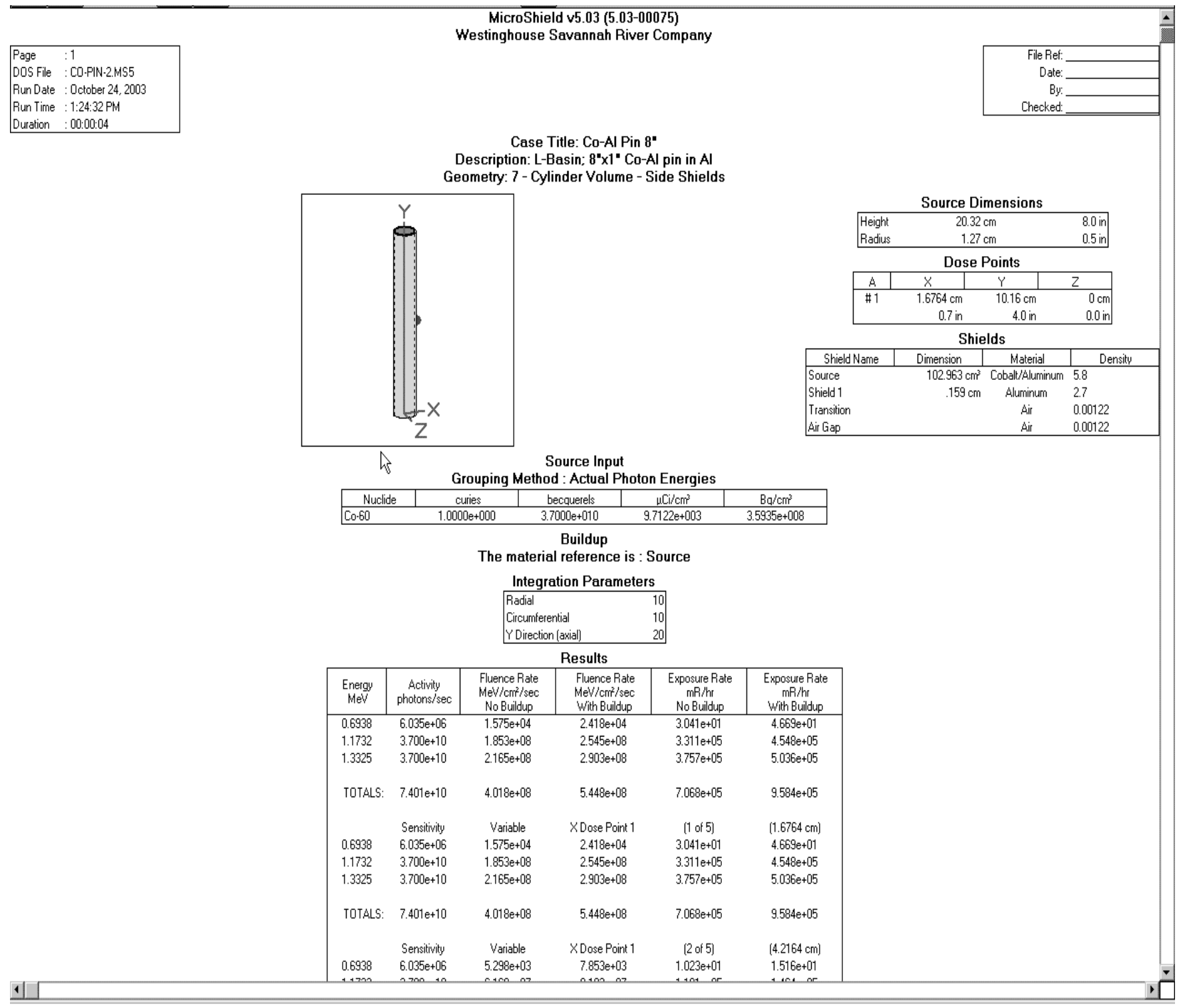


WSRC-TR-2003-00444

Revision 0

December 10, 2003

Page 41 of 41

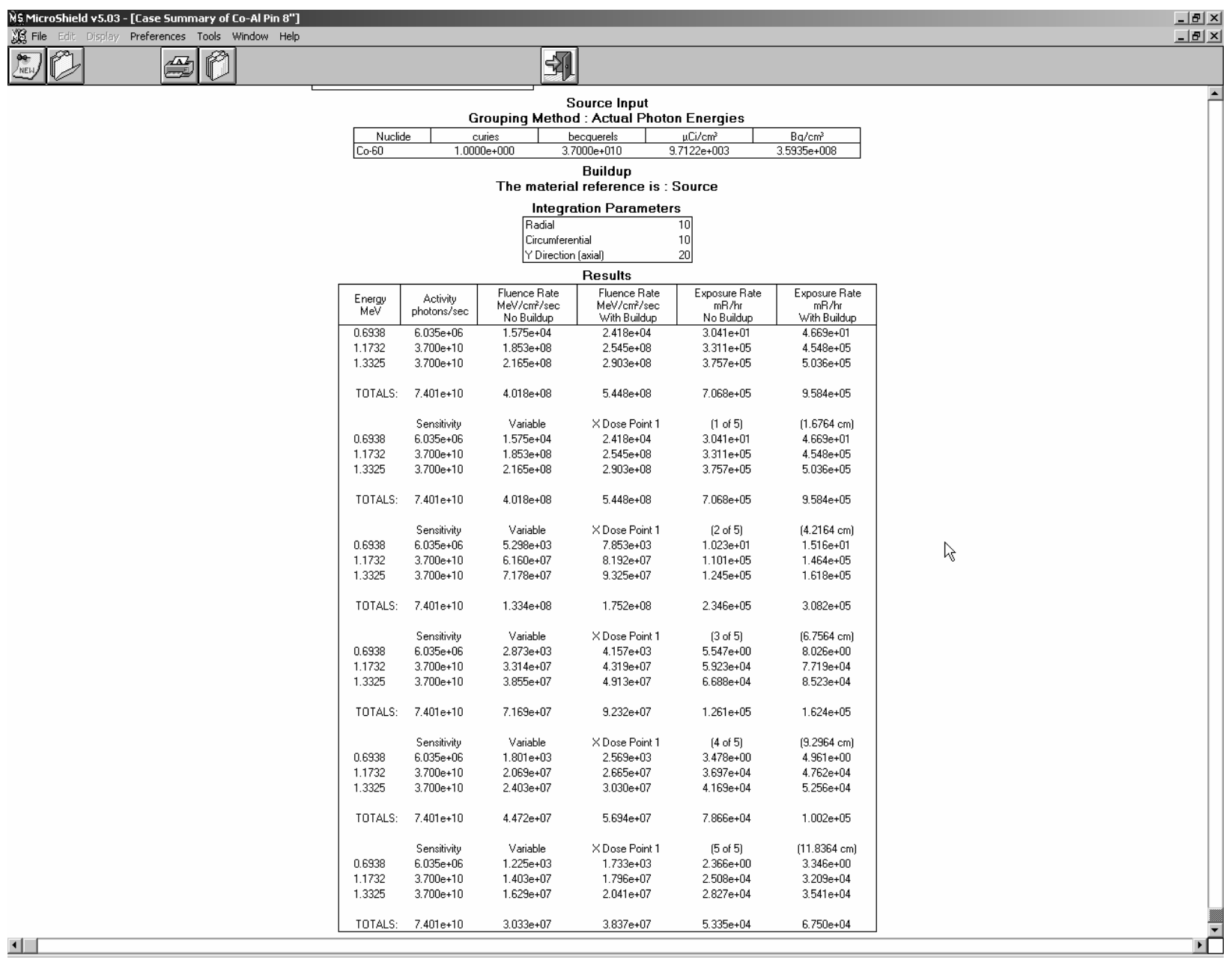

Total exposure rate for 8 " cobalt slug $=3.19 \mathrm{E} 5 \mathrm{mR} / \mathrm{hr}$

Total exposure rate for curium sampler slug containing 1/16" $\mathrm{x} 1 / 16$ " cobalt wire $=1.09 \mathrm{E} 6 \mathrm{mR} / \mathrm{hr}$

Ratio geometry correction factor (air) $=1.09 \mathrm{E} 6 / 3.19 \mathrm{E} 5=3.42$

Correction for Basin Water Absorption $=3.42 / 0.95=3.60$ 